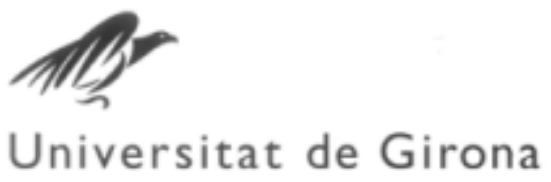

\title{
A HYBRID APPROACH OF KNOWLEDGE- BASED REASONING FOR STRUCTURAL ASSESSMENT
}

\author{
Luis Eduardo MUJICA DELGADO
}

ISBN: 978-84-690-7684-2

Dipòsit legal: GI- I I 15-2007 


\section{A HYBRID APPROACH OF KNOWLEDGE-BASED REASONING FOR StruCTURAL ASSESSMENT}

by

\section{Luis Eduardo Mujica Delgado}

Advisor

Dr. Josep Vehí

DOCTORAL THESIS

Girona, Spain

March, 2006 



\section{A HYBRid APPROACH OF KNOWLEDGE-BASED REASONING FOR StRUCTURAL ASSESSMENT}

A dissertation presented to the Universitat de Girona in partial fulfillment of the requirements of the degree of DOCTOR OF PHILOSOPHY

By

Luis Eduardo Mujica Delgado

Advisor

Dr. Josep Vehí Casellas 



\title{
ABSTRACT
}

\section{A Hybrid APPROACH OF KNOWLEDGE-BASED REASONING FOR StRUCTURAL Assessment}

\author{
by Luis Eduardo Mujica Delgado
}

ADVISoR: Dr. Josep Vehí

March, 2006

Girona, Spain

Maintenance and continuous health monitoring of structures is one of the most important field of research in a wide range of industries. It minimises not only costs but also improves safety. This research work describes a hybrid reasoning methodology for damage assessment in structures. This methodology is a combination of three major elements: i) vibration analysis - modelling and experiments, ii) advantage signal processing for features extraction or dimensionality reduction and iii) damage identification using knowledge-based reasoning. The work, involves various elements related to classical mechanics (vibration analysis), mathematics (wavelets, statistical process control), signal/pattern analysis/processing (knowledge-based reasoning, self organizing maps), smart structures (integrate piezoceramic sensors) and damage detection. Approaches are numerically and experimentally validated considering as structural damage: corrosion, mass reduction, adding masses, and impact loads. Structures used along all this work are: numerical model of a cantilever truss, aluminium beam and its numerical model, a pipe section of 4.28 meters length and its numerical model, a long pipe of 80 meters length and a part of a wing aircraft. Results and discussion are presented with some depth. Conclusions are presented with the emphasis on the advantages and drawbacks of using knowledge-based reasoning and statistical process control in structural assessment. 

Dedicated to my wonderful family: Magda Liliana,

Esteban, and his brother/sister who we are wishing. 



\section{Acknowledgments}

This doctoral thesis is the result of many efforts not only mine, but also from many people who directly or indirectly have collaborated with me. However, in few time and after four years it is very difficult to remember all of them. Therefore, I apologize in advance for not including in these lines people who really also deserve it.

In first place, I would like to express my gratitude to Dr. Josep Vehí Casellas, who since the beginning trusted in my responsibility, knowledge and abilities to participate in the European project PIEZODIAGNOSTICS. On the other hand, for the sake of his wide view and optimism, this doctoral thesis was born and du to his guidance it was kept alive.

To Professor Jose Rodellar Benedé from Universitat Politécnica de Catalunya, responsible (together with Dr. Josep Vehí) of the tasks entrusted by the project, who with his experience and patience helped me to understand how to express the ideas in writings: reports, papers, etc.

To the the 5FP Research Project G1RD-2001-00659(2002-2005), Smart Structural Diagnostics using Piezo-Generated Elastic Waves - PIEZODIAGNOSTICS, supported by the European Commission and all the partners: CEGELEC, TWI, ATKINS, CEDRAT, CDRiA, CIMNE, IFTR, ECL, ALSTOM, who provided mock-ups, structures, experiments and simulations which were essential for the development of this work.

To the Spanish government through the coordinated research projects DPI2003-07146-C02-02 and DPI2004-07167-C02-02 and by the government of Catalonia through 205SGR-00296.

To Professors Wieslaw Staszewski and Keith Worden from University of Sheffield who hosted me in their research group, giving me the opportunity of using their facilities and experiments. Furthermore, their guidance, comments and suggestions helped me to make reality some ideas.

To Przemyslaw Kolakowski from the Polish Academy of Sciences for providing information, experience, experiments, numerical models and data for starting the research presented today.

To Professor Michel Verleysen from Université Catholique de Louvain, Research Director of the Belgian National Fund for Scientific Research who contributed with knowledge, experience, suggestions and new ideas

To Dr. Gurkan Sin from University of Ghent who among laughs and informal meetings gave me important suggestions and ideas.

To the University of Girona (UdG) which has given me economical support during all this period thought of the research scholarship "Beca de Recerca UdG BR02/02"

To ESF Unit for Physical \& Engineering Sciences (PESC) through ESF Programme Innovation Control Technologies for Vibration Sensitive Civil Engineering Structures (CONVIB) and University of Girona for the economical support during my visit research to the Department of Mechanical Engineering at the University of Sheffield.

To Drs Gabriel Ordoñez, Gilberto Carrillo, Roberto Martínez and Oscar Gualdrón, professors and guides during my engineering studies at the Industrial University of Santander (UIS) in Colombia, who motivated me to start the PhD. studies.

To members of MICELab research group for their friendship and support during this time.

To my family in Colombia: Luis Hernando (father), Flor María (mother), Hernando Alonso y César Augusto (brothers), and Carolina (sister), who from the distance always encouraged me to keep jumping obstacles in the life.

To my family in Spain: Colombian and Latino-American people who, thanks to the often "cultural meetings", have done more comfortable the life.

To the life for giving me the opportunity of knowing lovely countries, wonderful people, amazing cultures, exciting history and enricher experiences.

Last but not least, thanks to my wife: Magda, who as $\mathrm{PhD}$ mate gave me invaluable suggestions and what is more, together with our son: Esteban, have sacrificed nights, days, even weeks of family time. 



\section{Brief Contents}

Detailed contents $\quad$ xi

Introduction 1

Paper 1:

$\begin{array}{ll}\text { A Hybrid Approach of Knowledge-Based Reasoning for Structural Assessment } & 17\end{array}$

Paper 2:

Impact Damage Detection in Aircraft Composites Using Knowledge-Based Reasoning 35

\begin{tabular}{|l|}
\hline Paper 3: \\
\hline \hline Multivariate Statistics Process Control for Dimensionality Reduction in Structural \\
\hline \hline Assessment
\end{tabular}

Paper 4:

Two Approaches to Structural Damage Identification: Model Updating versus Soft

Computing

Paper 5:

Comparison of Two Software Tools for Damage Identification: Gradient-based vs.

$\begin{array}{ll}\text { Case-Based Approach } & 101\end{array}$

Paper 6:

\begin{tabular}{|l|l|} 
Non-Destructive Testing for Assessing Structures by Using Soft-Computing & 111
\end{tabular}

\begin{tabular}{ll}
\hline Results and Discussion & 127
\end{tabular}

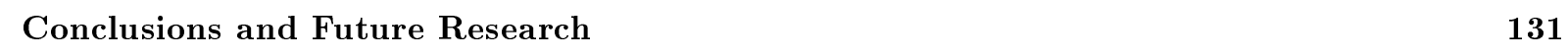

\begin{tabular}{ll}
\hline References & 135
\end{tabular} 



\section{Detailed contents}

Detailed contents $\quad$ xi

Introduction 1

$1 \quad$ Structural Damage Identification . . . . . . . . . . . . . . . . . . . . . 1

$2 \quad$ Motivation for Vibration-Based Damage Identification (VBDI) $\ldots \ldots \ldots \ldots \ldots$. . . . . 1

$3 \quad$ Strategies for Solving the Vibration-Based Damage Identification (VBDI) Problem . . . . 3

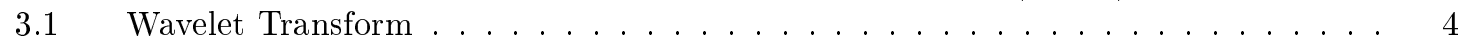

$3.2 \quad$ Neural Networks $\ldots \ldots \ldots \ldots \ldots \ldots \ldots \ldots \ldots$

$3.3 \quad$ Genetic Algorithms . . . . . . . . . . . . . . . . . . . . 4

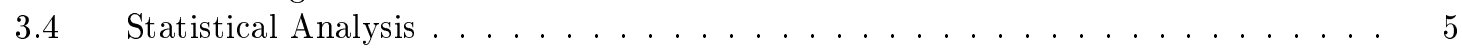

3.5 Knowledge-Based Approaches $\ldots \ldots \ldots \ldots \ldots \ldots \ldots \ldots$

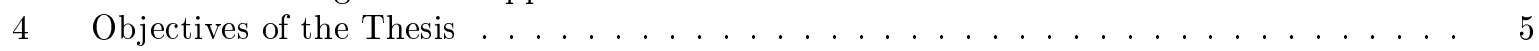

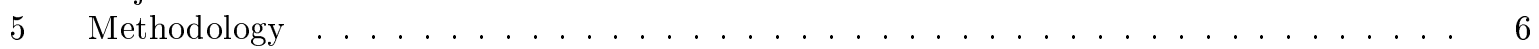

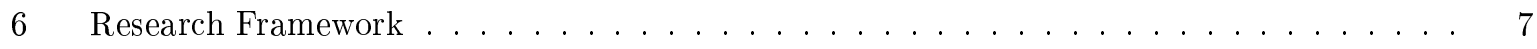

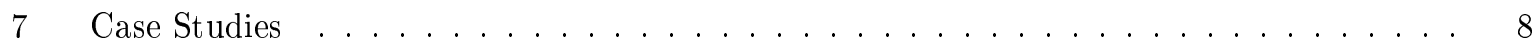

$7.1 \quad$ Numerical Model of a Cantilever Truss Structure $\ldots \ldots \ldots \ldots$. . . . . . . 8

$7.2 \quad$ Aluminum Beam and its Numerical Model . . . . . . . . . . . . . . . . . . . 8

$7.3 \quad$ Pipe Section and its Numerical Model . . . . . . . . . . . . . . . . . 10

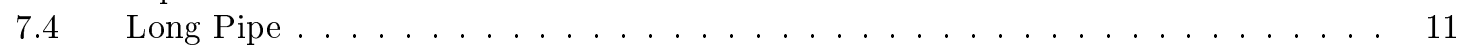

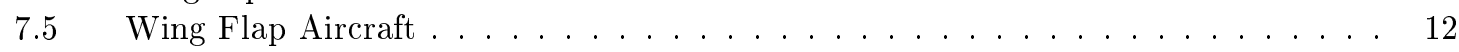

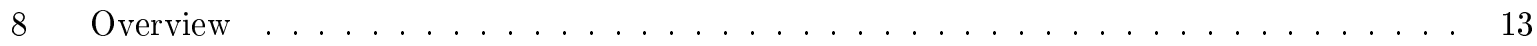

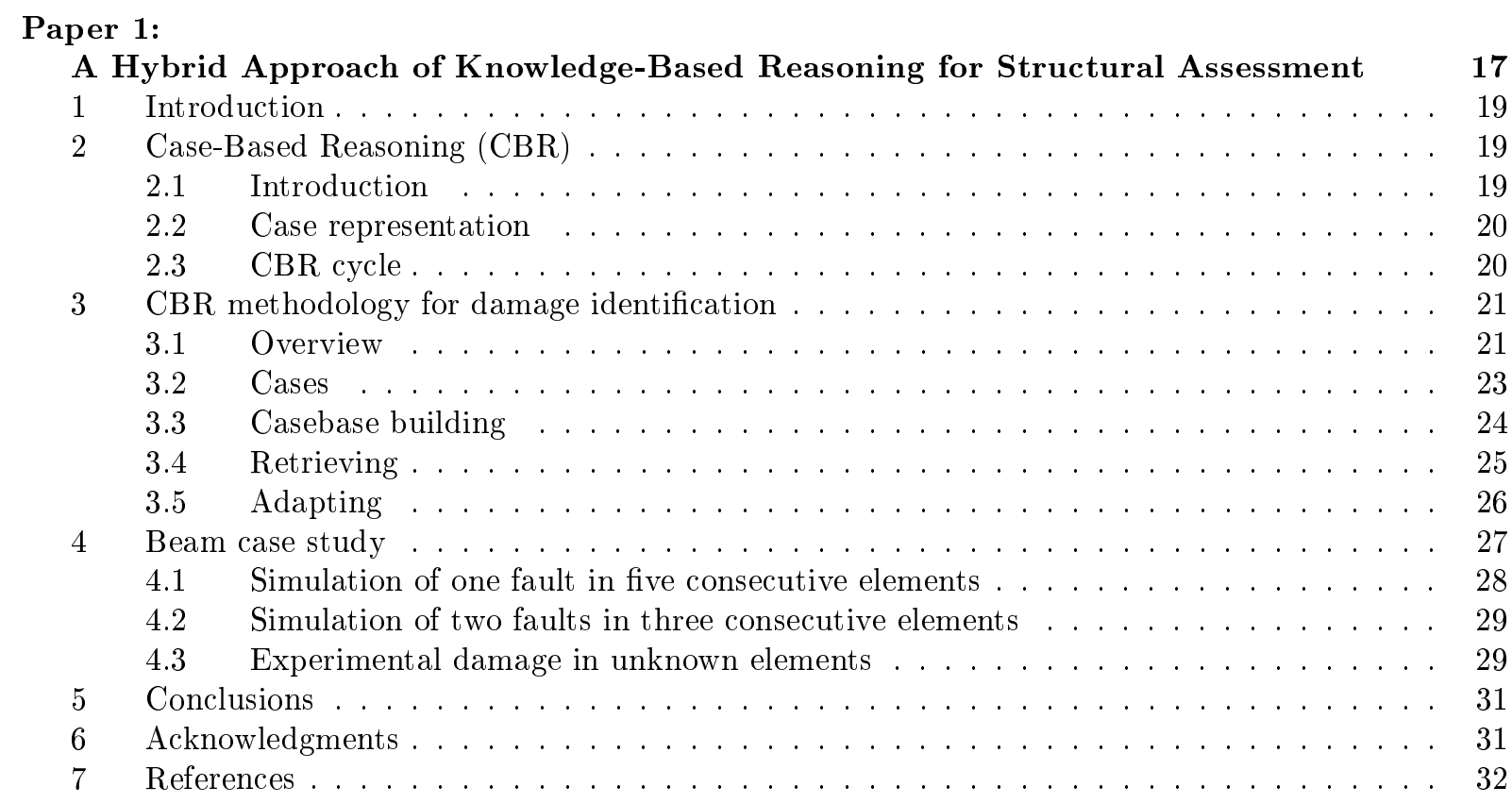

Paper 2:

Impact Damage Detection in Aircraft Composites Using Knowledge-Based Reasoning 35

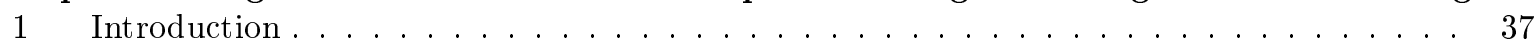

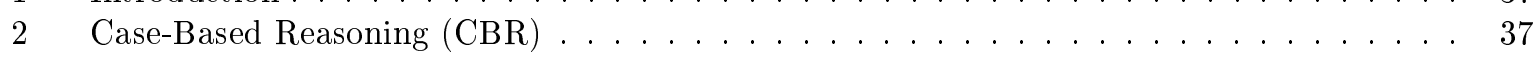

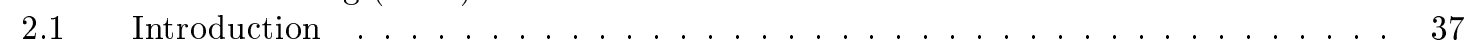




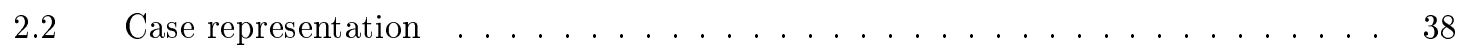

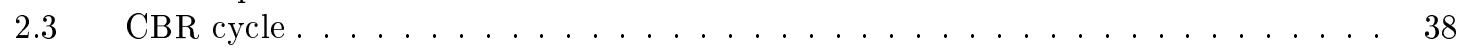

3 Experimental procedure . . . . . . . . . . . . . . . . . . . . . . . 39

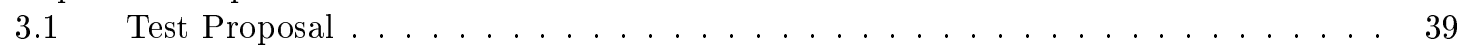

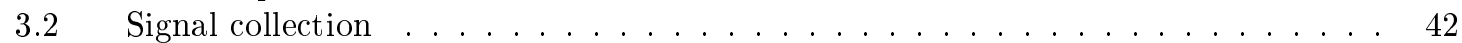

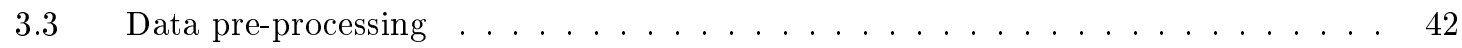

$4 \quad$ Impact location identification . . . . . . . . . . . . . . . . . . . . . . . . . 43

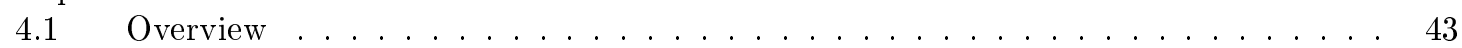

$4.2 \quad$ Casebase building . . . . . . . . . . . . . . . . . . . . . . . . . . . . . . . . . . . . . . . 44

4.3 Retrieving . . . . . . . . . . . . . . . . . . . . . . . . . . . . . . . . . . . . . 45

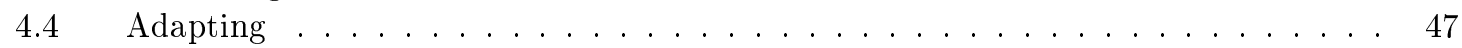

5 Experimental results . . . . . . . . . . . . . . . . . . . . . . . . . 48

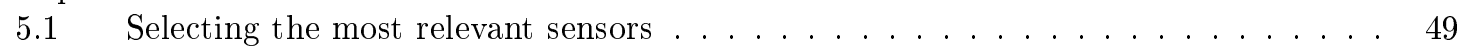

5.2 Using the signals of all sensors . . . . . . . . . . . . . . . . . . . . . . . . 50

$5.3 \quad$ Selecting sensors closest to the impact . . . . . . . . . . . . . . . . . . 51

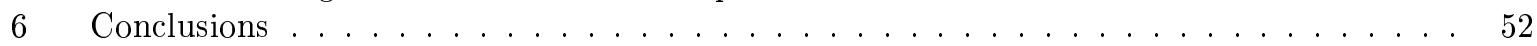

7 Acknowledgments . . . . . . . . . . . . . . . . . . . . . . . 52

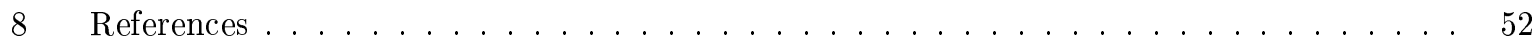

\section{Paper 3:}

Multivariate Statistics Process Control for Dimensionality Reduction in Structural Assessment $\quad \mathbf{5 5}$

$1 \quad$ Introduction . . . . . . . . . . . . . . . . . . . . . . . . . 57

$2 \quad$ Experimental procedure: an aircraft structure . . . . . . . . . . . . . . . . . . 58

$2.1 \quad$ Wing Flap Structure . . . . . . . . . . . . . . . . . . . . . . . . 58

$2.2 \quad$ Impact Method . . . . . . . . . . . . . . . . . . . . . . . 59

$2.3 \quad$ Data collecting . . . . . . . . . . . . . . . . . . . 59

3 Linear Dimension Reduction: Multivariate Statistical Process Control (MSPC) . . . . . . 61

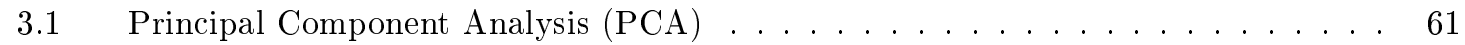

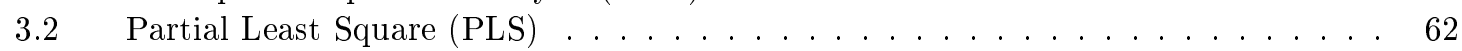

$3.3 \quad$ Multiway Principal Component Analysis (MPCA) . . . . . . . . . . . . . . . . . . 62

$3.4 \quad$ Multiway Partial Least Square (MPLS) $\ldots \ldots \ldots$. . . . . . . . . . . . . . . 63

$4 \quad$ Nonlinear Dimension Reduction: SOM and CDA . . . . . . . . . . . . . . . . . . 64

$4.1 \quad$ Self Organizing Map (SOM) . . . . . . . . . . . . . . . . . . . . . 64

$4.2 \quad$ Curvilinear Distance Analysis (CDA) . . . . . . . . . . . . . . . . . . . 64

5 Dimensionality reduction for locating impact damage in structures . . . . . . . . . . . . . 65

$5.1 \quad$ Impact location identification using Case Based Reasoning. . . . . . . . . . . . . . 65

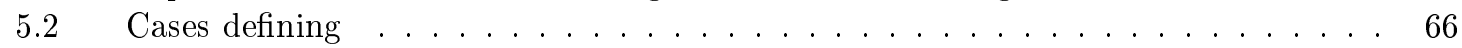

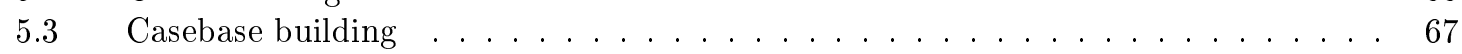

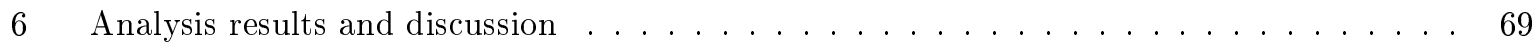

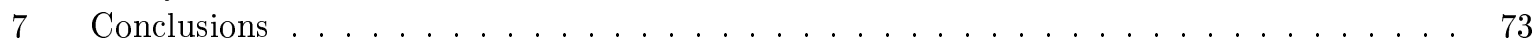

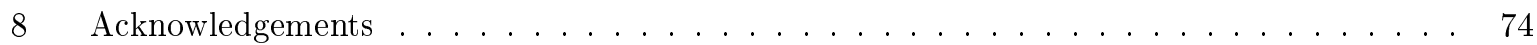

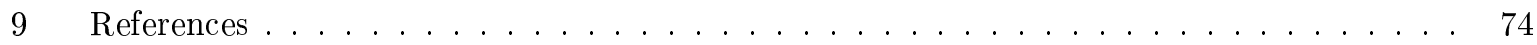

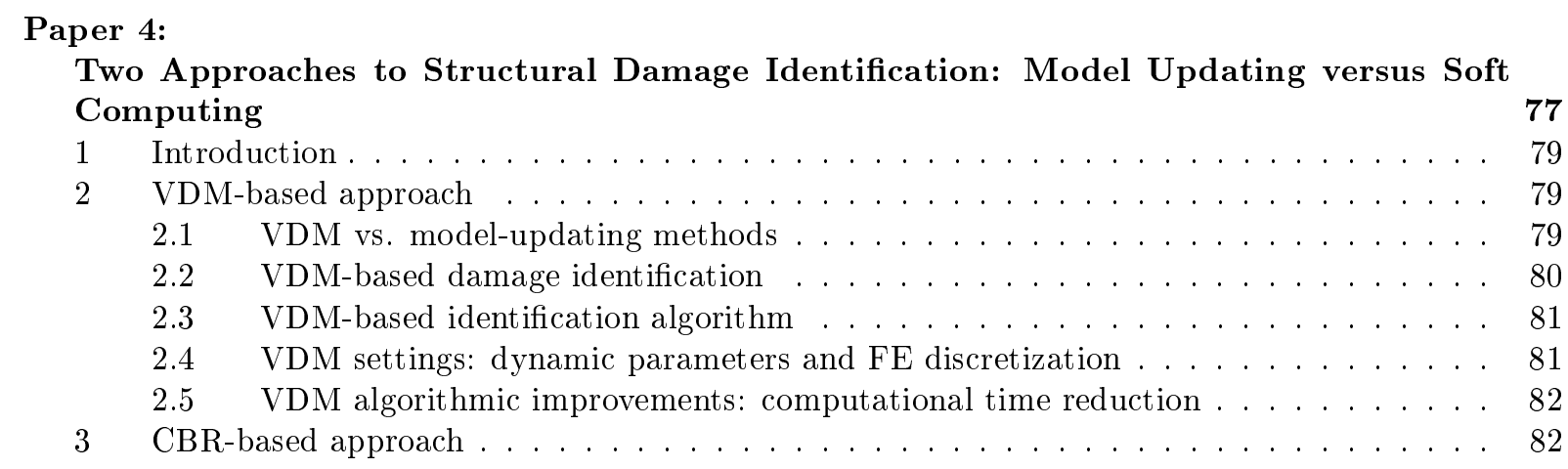


$3.1 \quad$ CBR vs. soft-computing methods . . . . . . . . . . . . . . . . . . . . 82

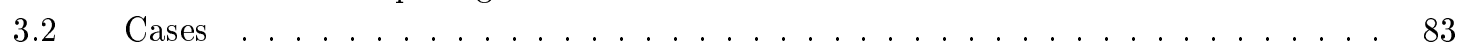

$3.3 \quad$ Casebase building . . . . . . . . . . . . . . . . . . . . . 83

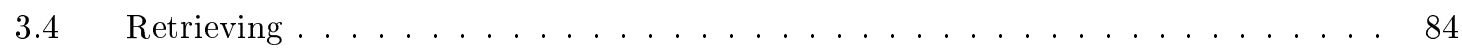

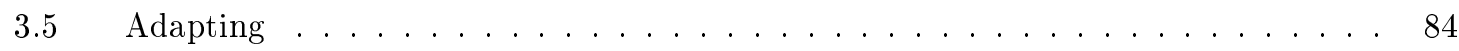

3.6 $\quad$ CBR-based identification algorithm. . . . . . . . . . . . . . . . . . . 85

$3.7 \quad$ CBR settings: representative casebases . . . . . . . . . . . . . . . . . . 85

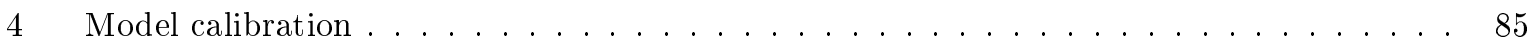

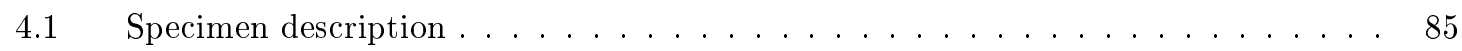

4.2 Excitation signal . . . . . . . . . . . . . . . . . . . . . . . . . . . . . . . . . . . . 86

$4.3 \quad$ Results for the undamaged structure . . . . . . . . . . . . . . . . . . . . 87

5 Numerical example of a beam . . . . . . . . . . . . . . . . . . . . . . . 88

$5.1 \quad$ Demonstration of the complexity of the inverse problem . . . . . . . . . . . . . 89

$5.2 \quad$ Comparison of the effectiveness of the two approaches . . . . . . . . . . . . . 91

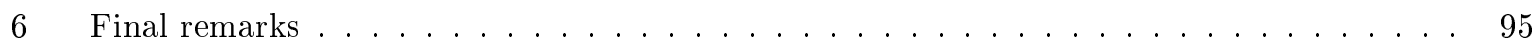

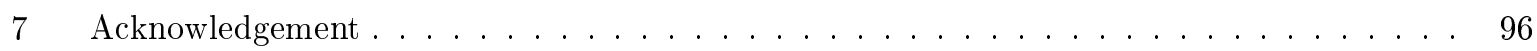

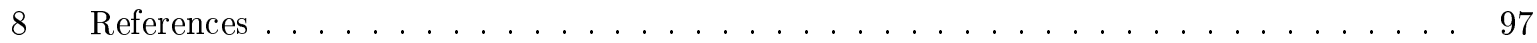

\section{Paper 5:}

Comparison of Two Software Tools for Damage Identification: Gradient-based vs.

Case-Based Approach

1 Introduction . . . . . . . . . . . . . . . . . . . . . . . . . 103

$2 \quad$ Characteristics of the two approaches . . . . . . . . . . . . . . . . . . . 103

$2.1 \quad \mathrm{VDM} \ldots \ldots \ldots \ldots \ldots \ldots$

2.2 CBR . . . . . . . . . . . . . . . . . . . . 104

3 Specific features of the two approaches . . . . . . . . . . . . . . . . . . . 106

3.1 VDM algorithm . . . . . . . . . . . . . . . . . . . . 106

3.2 VDM settings . . . . . . . . . . . . . . . . . . . . . 106

$3.3 \quad$ CBR algorithm $\ldots \ldots \ldots \ldots \ldots$. . . . . . . . . . . . . . . . . . . . . . . . . . . . . . . . . . . . . . . . 106

3.4 CBR settings . . . . . . . . . . . . . . . . . . . . . . 107

4 Numerical example . . . . . . . . . . . . . . . . . . . . . . . . 107

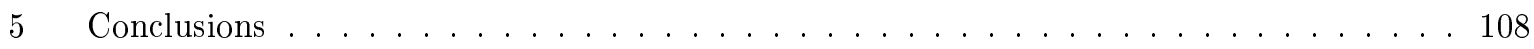

6 Acknowledgements . . . . . . . . . . . . . . . . . . . . . 109

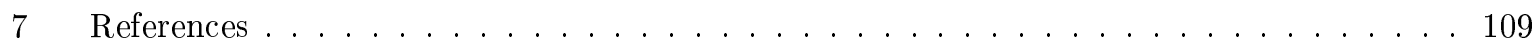

\section{Paper 6:}

Non-Destructive Testing for Assessing Structures by Using Soft-Computing 111

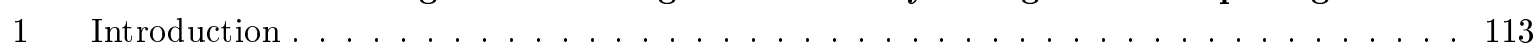

$2 \quad$ CBR methodology for structural assessment . . . . . . . . . . . . . . . . . . . . . . 113

$2.1 \quad$ Casebase building . . . . . . . . . . . . . . . . . . . . 114

2.2 Retrieving . . . . . . . . . . . . . . . . . . . . . . . 115

$2.3 \quad$ Adapting . . . . . . . . . . . . . . . . . . . . 116

3 Beam case study . . . . . . . . . . . . . . . . . . . . . . . 116

$4 \quad$ Pipe section case study . . . . . . . . . . . . . . . . . . . . . . . . . . . . 117

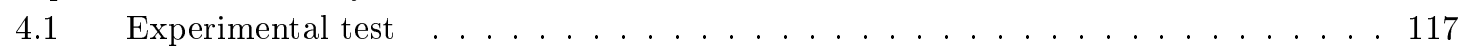

4.2 Numerical test . . . . . . . . . . . . . . . . . . . . . . . . 120

$5 \quad$ Long pipe case study . . . . . . . . . . . . . . . . . . . . . . . . . . 122

6 Conclusions . . . . . . . . . . . . . . . . . . . . . . . . 122

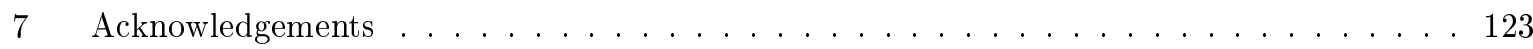

8 References . . . . . . . . . . . . . . . . . . . . . . . . . . . . 124

\begin{tabular}{lr}
\hline Results and Discussion & 127
\end{tabular} 


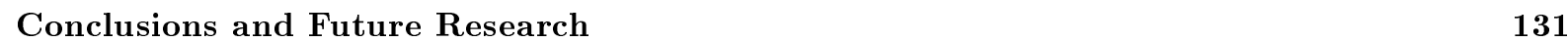

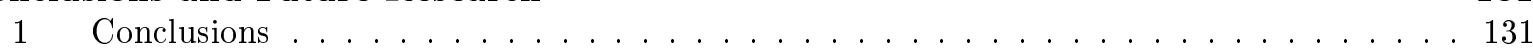

2 Main Contribution . . . . . . . . . . . . . . . . . . . . . . . . 132

3 Future Research . . . . . . . . . . . . . . . . . . . . . . . . 132

$3.1 \quad$ Dimensionality Reduction . . . . . . . . . . . . . . . . . . . . . 132

$3.2 \quad$ Numerical Modeling . . . . . . . . . . . . . . . . . . . . . . . . . 132

3.3 Reliability and Risk Analysis . . . . . . . . . . . . . . . . . . . . . . 133

3.4 Application in Real-Time Monitoring . . . . . . . . . . . . . . . . . . . . . . . 133

$4 \quad$ Contributions to Relevant Conferences and Workshops . . . . . . . . . . . . . . . . . . 133

\begin{tabular}{lr}
\hline References & 135 \\
\hline
\end{tabular} 


\section{Introduction}

\section{Structural Damage Identification}

The interest in the ability to continuously monitor a structure and detect damage at the earliest possible stage is shared throughout the civil, mechanical and aerospace engineering communities [FDN01]. Early damage detection and eventual estimation of damage is an important problem for any decision regarding structural repair and prevention of disasters. Damage in engineering systems is defined as intentional or unintentional changes to the material and/or geometric properties of these systems, including changes to the boundary conditions and system connectivity, which adversely affect the current or future performance of that system. Structural damage in normal service may include [DFP98] [FDN01]:

- Gradual (e.g. fatigue, corrosion, aging).

- Sudden and predictable (e.g. aircraft landings, planned explosions in confinement vessels).

- Sudden and unpredictable (e.g. foreign-object-impact, earthquake, wind).

Diagnosis of damage in structural systems requires the identification of the location and type of damage and quantification of the degree of damage. Rytter [Ryt93] defines four stages of damage monitoring:

- Level 1: Determination that damage is present in the structure.

- Level 2: Level 1 plus determination of the geometric location of the damage.

- Level 3: Level 2 plus quantification of the severity of the damage.

- Level 4: Level 3 plus prediction of the remaining service life of the structure.

To date, damage identification methods that do not make use of some structural model primarily provide Level 1 and Level 2 damage identification. When methods are coupled with a structural model, Level 3 damage identification can be obtained in some cases. Level 4 prediction is generally associated with the fields of fracture mechanics, fatigue-life analysis, or reliability and risk analysis.

Traditional nondestructive evaluation (NDE) techniques used for damage detection are either visual inspection or localized experimental methods such as acoustic or ultrasonic, optical, magnetic field, electrical and dielectric, radiography, eddy currents, thermal field, etc. All of these experimental techniques require that the location of the damage is already known and that the portion of the structure being inspected is readily accessible. Subject to these conditions, these experimental methods can detect damage on or near the surface of the structure.

\section{Motivation for Vibration-Based Damage Identification (VBDI)}

Limitations of traditional NDE techniques have motivated the research of new techniques that can be applied to in-service structures, reducing maintenance costs and improving safety, as well as system performance. In the Structural Health Monitoring (SHM) community, recent technological advances have renewed interest in damage detection research. Innovative sensing technologies, increased computational power, improvements in signal processing techniques, and the development of new material systems can all be continued to create self-sensing, automatically monitored structural systems with a broad range of potential applications.

The need for additional global damage detection methods that can be applied to complex structures has led to the development and continued research of methods that examine changes in the vibration characteristics of the structure. Doebling [DFP98] presents a comprehensive literature review of damage identification and health monitoring methods for structural and mechanical systems. This review focuses on methods based on vibration measurements and detection based on changes in vibration characteristics. 
Damages which alter the stiffness, mass or energy dissipation properties of a structure (e.g. corrosion), should be analyzed using an active system composed of actuators and sensors; the structure is exposed to known external energy inputs from the actuator (see figure 1). In other words, vibration-based damage identification is based on the phenomenon of strain-wave propagation. An excitation signal is applied and the dynamic response is examined. The damage will alter the measured dynamic response of the system.

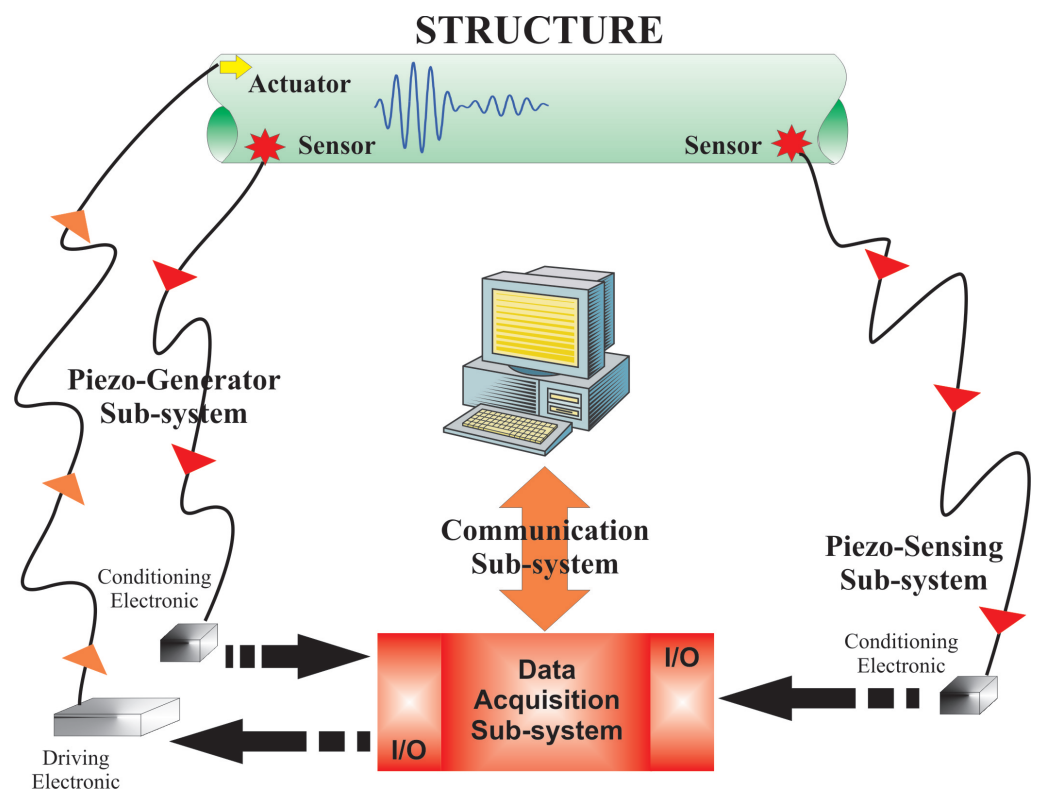

Figure 1: Active system for vibration-based damage identification

Detection and localization of sudden and unpredictable damages (e.g. impacts loads) on a structure are possible due to the propagation and attenuation of surface stress waves that result from an impact. This damage should be analyzed using a passive system, which consists of only sensors attached to a structure. The energy input to the structure is random and its source is usually unknown (see figure 2).

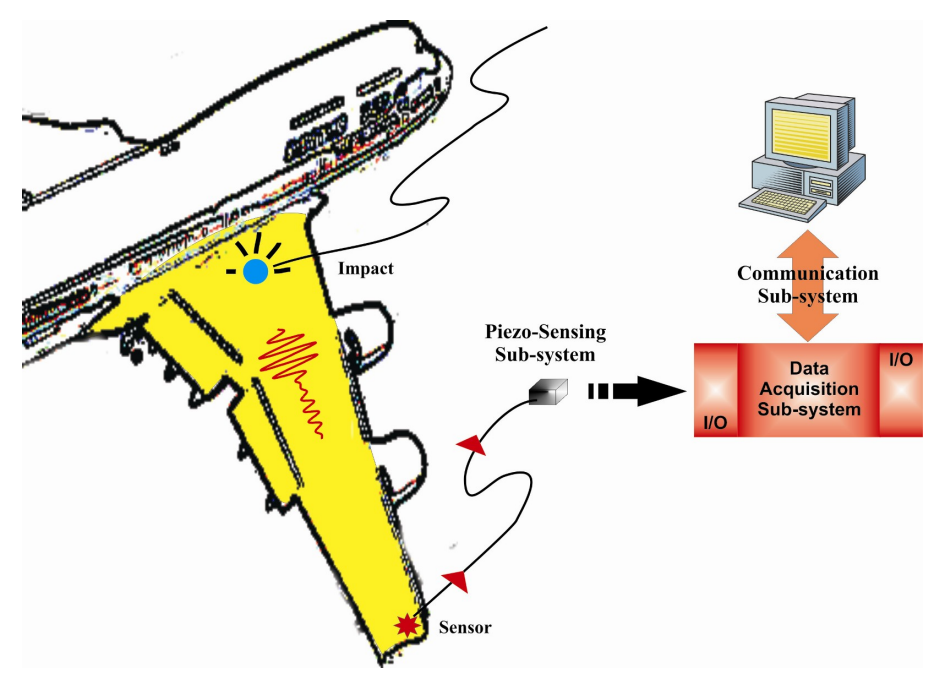

Figure 2: Passive system for vibration-based damage identification 


\section{Strategies for Solving the Vibration-Based Damage Identifica- tion (VBDI) Problem}

A very large body of work exists in the field of Vibration-Based Damage Identification (VBDI). Several extensive literature reviews have been compiled in the past several years, including an extensive survey of over 300 papers by Doebling [DFP98]. VBDI has been a very active area of research for many years. The first published example of vibration characteristics being used to identify damage to a structure was by Lifshits and Rotem in 1969 [LR69]. Much of the early research focused on health monitoring of offshore oil platforms, nuclear power plants and rotating machinery. In the 1980s the field expanded rapidly, especially in the areas of turbo machinery, civil and aerospace structures.

The process of implementing a VBDI involves the observation and determination of the operation conditions, data acquisition system, signal processing, modeling and strategy for damage identification in the strict sense. A VBDI system requires the availability of an appropriate signal processing method to analyze features from sensor data and to translate this information into a diagnosis of location and severity of damage. Overall, the processing chain includes preprocessing techniques, feature extraction and pattern recognition that allow distinguishing between the undamaged and the damaged structure [Sta02].

Data preprocessing often includes smoothing and denoising procedures, normalization, trend analysis and reduction of outliers [BSW $\left.{ }^{+} 00\right]$ [WMF00]. There exist a number of low-pass filters which can be used to smoothen the data: These include optimal smoothing procedures such as the Wiener filter based on Fourier analysis and Savitzky-Golay least squares and digital smoothing polynomial filters. Denoising procedures are normally based on the orthogonal wavelet transform. Normalization identifies relationships between measurements and features. Trends show unwanted temporal relationships in the data. Outliers are feature patterns which are statistically far from the normal selection of patterns used for training.

Feature selection is a process of choosing input for pattern recognition in order to reduce the number of features for training and thus to reduce dimensionality of feature space. Often both terms "feature extraction' and 'selection" are used synonymously. Feature extraction includes either signature or advanced signature analysis. Signature analysis employs simple feature extraction methods, based on data reduction procedures, which lead to scalar representations. This includes for example statistical spectral moments, physical parameters of the analyzed system or modal based criteria. Advanced signature analysis uses sets of features in the form of vectorial or pattern representations such as spectra, the envelope function or the amplitude of the wavelet transform. A number of advanced signature analysis procedures have been developed in the last few years, as discussed in [Sta02].

Chui [Chu97] pointed out that the local singularity in a time-sequence signal could be more clearly exhibited if the signal is decomposed using wavelet transform. Staszewski [Sta02] [Sta98b][Sta97a][Sta97b] shows that wavelet-based linear transformations for data compression in vibration analysis can be used not only for effective data storage and transmission but also for feature selection.

A set of features given by continuous, discrete or discrete-binary variables which are formed in vector or matrix representation is called a pattern. Patterns represent different conditions of an analyzed structure. Therefore, damage detection can be regarded as a problem of pattern recognition. Classical methods of pattern recognition use statistical and syntactic approaches. Statistical pattern recognition assigns features to different classes using statistical density functions. Syntactic pattern recognition classifies data according to its structural description. In recent years neural networks have been established as a powerful tool for pattern recognition [Wor97].

In damage detection theory, frequency domain methods such as modal analysis have been among the most popular approaches used to date. However, several methods exist that utilize time responses rather than modal data [CI97]. Most of these vibration-based health monitoring techniques include Artificial Intelligence and they usually apply wavelet transformations, artificial neural networks, genetic algorithms and statistical analysis, but until now, none of these included applied knowledge-based reasoning. 


\subsection{Wavelet Transform}

Wavelet Transform (WT) is a mathematical tool that can decompose a temporal signal into a summation of time-domain basis functions (subsignals) of various frequency resolutions. This simultaneous timefrequency decomposition gives the WT a special advantage over the traditional Fourier transform in analyzing nonstationary signals. When structural vibration response signals in the time domain are decomposed into multiple subsignals using wavelet transform, change corresponding to structural damage in each subsignal may manifest notable difference, and some of the subsignals may possess high sensitivity to small damage in structures [HNR00].

There is a growing number of publications reporting on system identification to structural assessment using wavelet techniques [Sta97a][Sta98a][PFMR00][GL01][HW03]. Chang and Sun [CS03a] propose wavelet packet signature (WPS) for locating and quantifying structure damage. These wavelet packets consist of a set of linearly combined usual wavelet functions. Yam et al. [YYJ03] construct structural damage features proxy vectors based on the energy variation of the structural vibration responses decomposed using wavelet package before and after the occurrence of structural damage.

\subsection{Neural Networks}

Doebling et al. [DFP98] cite some applications of Artificial Neural Networks (ANN) developed before 1997 to damage detection in structures. Some of them use static load, others use vibrations caused by earthquakes, crash, wind, etc. Nowadays, many studies have demonstrated that neural networks are a powerful tool for the identification of systems typically encountered in the structural dynamics field (structure-unknown identification) [YYJ03].

From another point of view, neural networks are used like a classifier or a pattern recognizer. A number of different network architectures available for pattern recognition include feedforward, recurrent and cellular networks [FP97]. The architecture and process of training a neural network depends on which level of damage identification is required. An unsupervised scheme (Kohonen networks) offers the possibility of novelty detection. A supervised learning scheme (Multi-Layer Perceptron [Wor97] [RL95], Radial Basis Functions [ZB93]) is required for location and severity of damage. It appears that often simple unitary networks are not sufficient for complex pattern recognition tasks. In such cases networks can be combined, using different approaches [Mar01a][Mar01b].

On the other hand, it has been demonstrated that neural networks are a powerful tool for locating impacts from signals received from piezoelectric sensors [HCSW05][SWWT00][WS00][JSFK95][LPW $\left.{ }^{+} 01\right]$.

\subsection{Genetic Algorithms}

To minimize the discrepancy between the mathematical model (computed responses) and a real structural system (measured responses), several types of formulations have been used in structural damage detection and identification problems. Equation error and output error approaches formulate the problem as an optimization problem [HS90] [CG01].

Genetic Algorithms (GAs) have been used for the minimization of the cost function defined from the differences between experimental and numerical eigenvalues and eigenvectors [LZ93], natural frequencies [MS96], mode shapes [CG96][YZ98], or their combinations [HX02][FPG98][RS97]. On the other hand, Staszewski used GAs in order to extract wavelet coefficients which represent the principal features in the time-scale [Sta97b]. Some modifications or improvements have been done from simple GA in order to reduce the size of the search space [MN02], and the sensitivity to noise [RL03].

On the other hand, GAs have been used for optimization tasks in sensor triangulation methodologies [CS03b] and an Adaptive Neuro Fuzzy Inference System (ANFIS) has been applied for impact locating and magnitude estimation [SK03].

Regardless of the fact that the GA-based structural damage detection has been successful, it requires repeated searching for numerous damage parameters so as to find the optimal solution of the objective function (measured data). When the measured data and the structural damage parameters to be determined are multitudinous, the efficiency of this method is often not feasible for online damage detection of in-service structures. 


\subsection{Statistical Analysis}

Statistical methods are essential in structural health monitoring recognizing the fact that there is always uncertainty present in the simulation model, the simulation input parameters, and the observed measurements [SG96][FDDN99][LZ99]. Structural health monitoring methods based on statistical pattern recognition classify the structure in various damage states based on the statistical difference between features extracted (via signal processing, parameter estimation, or some other technique) from the measured responses of the structure in the undamaged and damaged states. The key is to find and use features that are sensitive to damage.

Marwala applied the hybrid Monte-Carlo method to assign the weight vector of the neural network used to relate inputs and outputs in damage identification [Mar01a] [Mar01b]. To solve the problem of damage localization as a categorization problem, a stochastic pattern recognition method [TH03] has been presented. The method of outlier analysis based on the Mahalanobis distance was used to detect a lowest level of fault [WMF00].

Recently, techniques based on multivariate statistics [DFP98] [WM00] and Statistical Process Control (SPC) [FSF01] have been applied in structural damage detection. Sohn et al. [SCF00] used Principal Component Analysis (PCA) to perform data compression prior to the feature extraction process when data from multiple measurement points are available in order to enhance the discrimination between features from undamaged and damaged structures. Worden and Manson [WM99] implemented visualization and dimension reduction with PCA for damage detection. Zang and Imregun [ZI01] utilized the PCA technique to condense the Frequency Response Functions data and their projection onto the most significant principal components, which were used as the Artificial Neural Network input variables. De Boe and Golinval [BG03] analyzed a piezo-sensor array for damage localization by means of PCA.

\subsection{Knowledge-Based Approaches}

On the other hand, the approach in which an "expert" applies his/her experience and knowledge to a situation can frequently provide a solution to a problem without resorting to an intensive investigation [dMP97] [Wat98] [MC03]. The use of knowledge-based approaches to damage identification was suggested by Natke and Yao in 1993 [NY93]. Despite Case Based Reasoning (CBR) being used gradually in several domains such as diagnosis, prediction, control and planning [AP94] and winning attention, in Structural Health Monitoring, the author of this thesis knows of no references that have been used before this method for detecting damage. However, in the field of structural design, some researchers [ELJ94, KK96, LM96] have applied Case Based Reasoning to bridge design. Because many modeling possibilities exist to explain the behaviour of structures, Raphael and Smith [RS98, RNRS02b, RNRS02a] describe an approach for selecting appropriate causal models for engineering diagnostics. They combine compositional modeling with model reuse to improve the quality of diagnosis.

\section{Objectives of the Thesis}

In this thesis, the problem of vibration-based damage detection is investigated. The main objective was to develop a methodology to assess structures focusing on vibration analysis (modeling and experiments), signal processing (features extraction or dimensionality reduction) and damage identification using knowledge-based reasoning. The evaluation includes finding whether damage is present in the structure, and defining the geometric location of the damage and its severity.

More specifically, the objectives of this work are the following:

To develop a methodology to identify damages in structures based on vibration measures. These vibration measures can be provided by the response of the structure to an input excitation that can be either known (e.g. using piezoelectric generators) or random (e.g. object-impact). This methodology considers the damage identification problem as a problem of pattern recognition and introduces in Structural Health Monitoring (SHM) community techniques used in other engineering areas. 
To include Case Based Reasoning (CBR) in damage identification methodology.

Systems in which an expert applies his/her experience and knowledge to a situation can often provide a solution of the problem. It is proposed to solve the damage identification problem using CBR and combining it with other techniques which help improve the process and make it faster.

\section{To introduce Multivariate Statistical Process Control (MSPC) techniques in Structural Health Monitoring (SHM).}

Since Structural Health Monitoring (SHM) systems have many sensors measuring variables for a long time and this data often is highly correlated, redundant and noisy, Principal Component Analysis (PCA), Partial Least Square (PLS) and its Multiway extensions are proposed for reducing the dimensionality of the problem.

\section{To study the application of MSPC techniques and nonlinear methods for case retrieving into CBR methodology.}

Case retrieving is choosing from old situations those most similar ones to the current one. One way to do that is reducing dimensionality as much as possible. The aim is to use MSPC, Self- Organizing Maps (SOM) and Curvilinear Distance Analysis (CDA) techniques for case retrieving and result analysis.

To combine experiments (lab case and field case) with numerical simulations into the CBR methodology.

Considering that in civil, mechanical and/or aerospace structures, it is possible to utilize the numerical model only, or experiments in the lab only, or both, the proposed methodology should be able to demonstrate its feasibility in any of these circumstances.

To validate the developed methodology in several structures and different kinds of damage. Since the main objective was to assess structures, various structures (cantilever truss, aluminum beam, pipe section, long pipe and wing flap aircraft) were considered and several defects were studied (corrosion, mass reduction, adding masses, and impact loads).

\section{$5 \quad$ Methodology}

To accomplish the objective of developing Knowledge-Based Reasoning methodology for damage identification in structures, the work has been performed through case studies.

In a first step, numerical simulations of the dynamic behavior of simple structures has been performed. Once the core methodology has been developed, it has been validated by laboratory experiments. The first aim has been to locate and identify mass reduction in simple structures. The structure is excited by an actuator, which produces a vibration input signal with known parameters. The lone sensor, located at the end of the structure, measures its dynamic response at this point. A numerical example of a cantilever truss structure (discrete example) and an aluminum beam structure modeled with a few elements (one dimension), were used to simulate the dynamic responses with different damages. These data were processed using wavelet transform and were organized by means of self-organizing maps. From simulated dynamic responses of unknown damages, these damages can be detected and identified using Case-Based Reasoning. This first approach was validated using numerical simulations for training and lab experiments for testing. In the aluminum beam structure, a damage is produced ( $1 \mathrm{~mm}$ deep cuts on the distance of $1 \mathrm{~cm}$ ). The numerical model was calibrated well enough (for starting damage identification). Until now, either only simulations or combination of simulations and experiments, were considered.

The second step has been to test more complex structures, a pipe section in a laboratory, using the experimental setup of a pipe section and its Finite Element Method model. Due to calibration problems of the structure with its numerical model, the validation was performed separately. This structure has a greater level of difficulty as it uses four sensors to collect the dynamic response. Strategies for analyzing all this information have been developed, and the configuration of actuators and sensors has been analyzed. Several mass reduction damages were simulated; the dynamic responses were processed and organized. The validation has been carried out using damages not included before. Several experiments with reversible damages have been performed in a laboratory. These damages consist in adding masses over the surface of the pipe. 
In a third step, a field test consisting of a long pipe has been used to validate the whole methodology in operating conditions. Due to the high cost of building a numerical model, only experiments were carried out. Several reversible damages have been performed, including the addition of different masses at different locations over the surface of the pipeline. This system has only one sensor but, it is located far from the actuator.

Finally, the methodology has been extended to a more complex structure consisting of a wing flap. Laboratory experiments have been carried out to detect and locate impacts. In this experiment, multiple sensors were located over the surface to measure the strain waves produced by the impact. In this case, the aim was, besides analyzing correlation between sensors, to solve the problem in two dimensions, since the location implies to find an $x$ location and a $y$ location. Multivariate Statistical Process Control (MSPC) has been introduced for dimensionality reduction considering correlation between the data, and case retrieving into CBR methodology.

\section{Research Framework}

Part of this work has been obtained on the basis of the research project entitled "PIEZODIAGNOSTICS: Smart Structural Diagnostics Using Piezo-Generated Elastic Waves". This project was funded by the European Community under the Competitive and Sustainable Growth programme of the Fifth RTD Framework Programme (1998-2002) under contract G1RD-2001-00659.

The main objective of the PIEZODIAGNOSTICS project was to develop a prototype long-range monitoring system applicable to a variety of industrial installations suffering from structural degradation, particularly by corrosion, based on piezo-generated wave propagation. This new structural diagnosis environment uses long -distance propagation of low-frequency guided waves. It is based on the concept that interaction of the vibration waves with localized structural change (damage) will characteristically modify the shape of the propagating signal. Therefore, information about the size, location and type of damage can be deduced from the difference in detected pulse shape between the original structure and the structurally altered structure.

The project concentrated on reaching two major goals. The first goal was to check the ability of piezo devices for inducing (actuators) and collecting (sensors) the low-frequency (below $1 \mathrm{kHz}$ ) structural vibration response. The second goal was to develop an associated data processing methodology enabling real-time monitoring, multidamage detection and precise identification of damage.

Two software packages were developed using two independent approaches. The first approach, the Virtual Distortion Method (VDM) developed by the SMART-TECH Centre (STC), belongs to the class of model-updating methods. It uses gradient-based optimization techniques in damage-identification algorithms. The second approach belongs to the class of soft-computing methods and uses Case-Based Reasoning methodology to identify damages by analogy, a methodology that is the heart of this doctoral thesis.

The partners involved in the PIEZODIAGNOSTICS project are six companies and three universities. Partners that have closely collaborated with the development of the methodology presented throughout this thesis, providing the structures and some of its numerical models for testing are the following:

IFTR (Institute of Fundamental Technological Research). Among the laboratories and centers that operate at IFTR of the Polish Academy of Sciences in Warsaw, the Smart Technology Centre (SMART-TECH) works on issues of safety and integrity of engineering systems focusing, among others, on intelligent materials (e.g. Piezo-Electrics), actuators, and acoustic-electronic systems for damage detection and identification. This center provided the aluminum cantilever beam structure and its numerical model based on the Virtual Distortion Method (VDM).

ALSTOM CERG (Centre d'Etudes et de Recherches de Grenoble). The ALSTOM research center is involved in fluid mechanics. It is a part of the company called ALSTOM Fluides et Mécanique SA, a supplier of pumps and pumping stations. This company provided facilities for testing a pipe section of $4.28 \mathrm{~m}$ length. The numerical model of this pipe section was developed using the Finite Elements Method (FEM) by CIMNE (International Center for Numerical Methods in Engineering, partner of the project as well) in cooperation with ALSTOM CERG. 
CEGELEC NDT (Nondestructive Testing). The CEGELEC NDT unit supplies Nondestructive Testing systems and services to the nuclear power plant industry and other industrial installations. The CEGELEC NDT unit develops various methods of inspection. Inspection of vessel reactors and bimetallic welding of nozzle or pipes subject to constraint are examples of important areas within the nuclear power plant field. Inspection of fuel storage tanks and ship structures are other important fields of the CEGELEC NDT unit activities. This company provided an $80 \mathrm{~m}$ long pipe and performed the experiments. Due to the complexity of the structure, no numerical model was developed.

All these structures were excited with piezo-actuators and their structural response was measured by piezo-patch sensors. Piezo-generators and piezo-sensors were designed and supplied by Cedrat Recherche SA-CEDRAT- (partners in the project) and CEGELEC NDT respectively.

On the other hand, the Dynamics Research Group that operates at the University of Sheffield, is an internationally recognized centre of Excellence specialized, among other areas, in Structural Health Monitoring. There, experiments of impact loads were performed on a part of an aircraft wing flap. The methodology, the basis of this research, was tested detecting and locating impacts with the collaboration of Professors Wieslaw Staszewski and Keith Worden.

\section{$7 \quad$ Case Studies}

\subsection{Numerical Model of a Cantilever Truss Structure}

The most simple case study is a numerical example of a cantilever truss structure with eight sections (see figure 3). This numerical model is performed using the Virtual Distortion Model and it is provided by SMART-TECH Centre. The material and the geometric specifications have been previously assigned. Two antiphase sine excitation forces were applied to elements 36 and 38 . The element 1 was chosen as the sensor to receive the propagated wave. The structural dynamic response was simulated using the damages of mass reduction between $5 \%$ and $60 \%$ in 11 scenarios of damage.

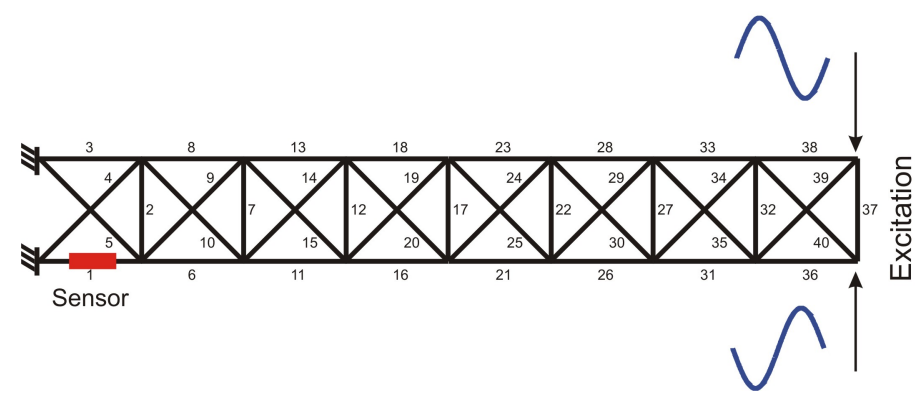

Figure 3: Cantilever truss structure

\subsection{Aluminum Beam and its Numerical Model}

The experimental aluminum beam and its numerical model were provided by SMART-TECH Centre. Its physical characteristics are shown in Table 1. It is equipped with a piezoelectric actuator (see figure $5 \mathrm{a}$ ) and a sensor (see figure $5 \mathrm{p}$ ) that measures the bending strains (curvature) at the specified location. A numerical model using the Virtual Distortion Method is considered, as illustrated in figure 4. The first results were obtained using the sine wave excitation signal of the $142.8572 \mathrm{~Hz}$ frequency with only one period duration and a numerical model with 102 elements. To obtain the last results, a 2.5-cycle and a 4.5-cycle Hanning windowed sine pulses with $491 \mathrm{~Hz}$ frequency, which corresponds to the seventh eigenfrequency of the beam, were applied and the numerical model consisted of 49 elements. Several structural damaged dynamic responses were simulated (up to 10 consecutive elements with 12 different reductions of mass). Experimental damage was caused to the real structure (see figure 6). 
Table 1: Material of the beam.

\begin{tabular}{lcc}
\hline \hline Material & Young's Modulus $(G P a)$ & Density $\left(\mathrm{kg} / \mathrm{m}^{3}\right)$ \\
\hline aluminum & 65.78 & 2710 \\
steel fixing & 207 & 7680 \\
truss rod (piezo actuator) & 0.28 & 7117 \\
\hline \hline
\end{tabular}

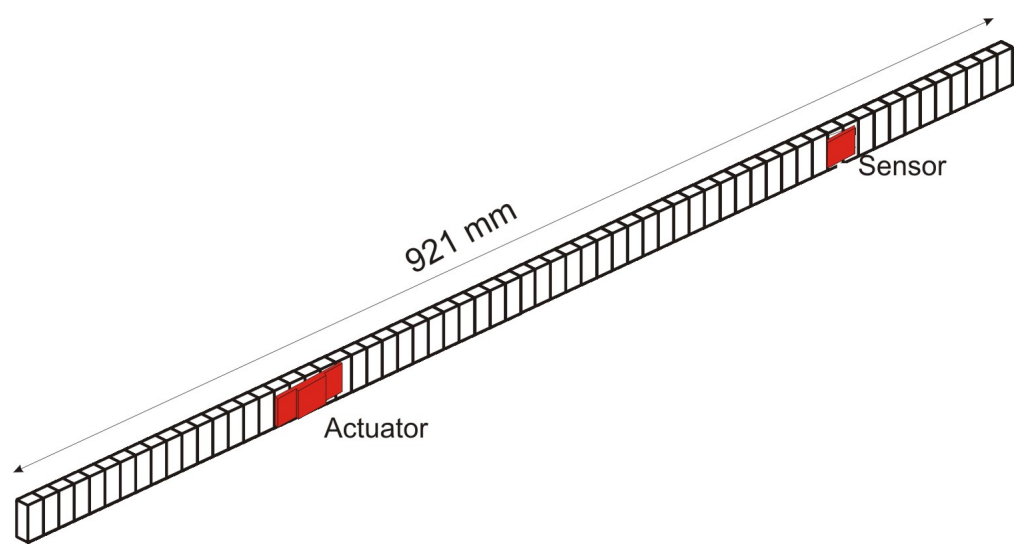

Figure 4: Beam model

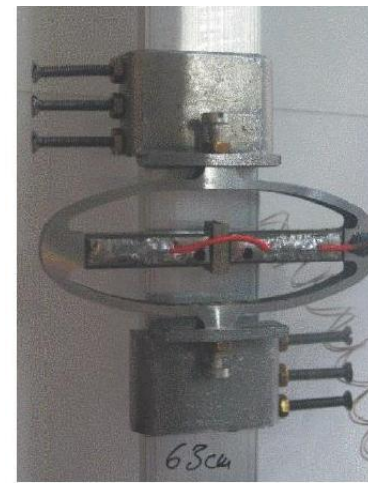

a)

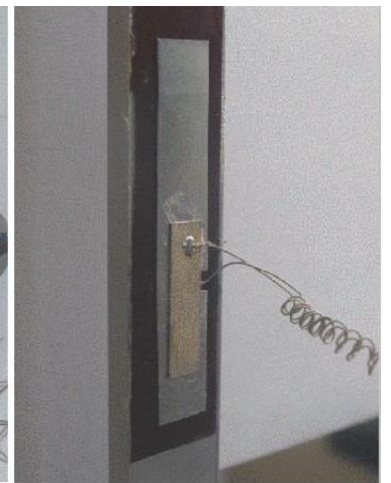

b)

Figure 5: (a) Actuator (b) Sensor

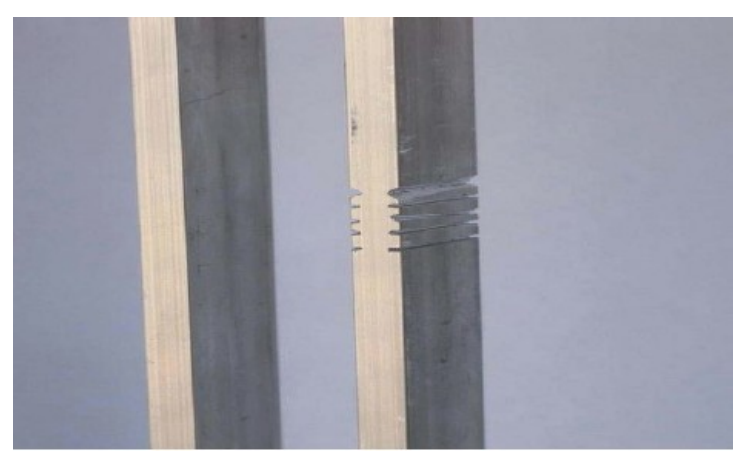

Figure 6: Original and damaged beam 


\subsection{Pipe Section and its Numerical Model}

ALSTOM CERG provided a pipe section and configured the experimental setup shown in figure 7 . The material of this pipe section is stainless steel. It has an internal diameter of $80 \mathrm{~mm}$, thickness of $2 \mathrm{~mm}$ and its useful length is $5550 \mathrm{~mm}$. It was excited using a 7-cycle Hanning windowed sine pulse with 750 $\mathrm{Hz}$ frequency, near its first radial-axis mode, using a generator supported as shown in figure 8 . Four sensors measure the dynamic response of this structure. Reversible defects have been performed. Five masses have been added in different positions.

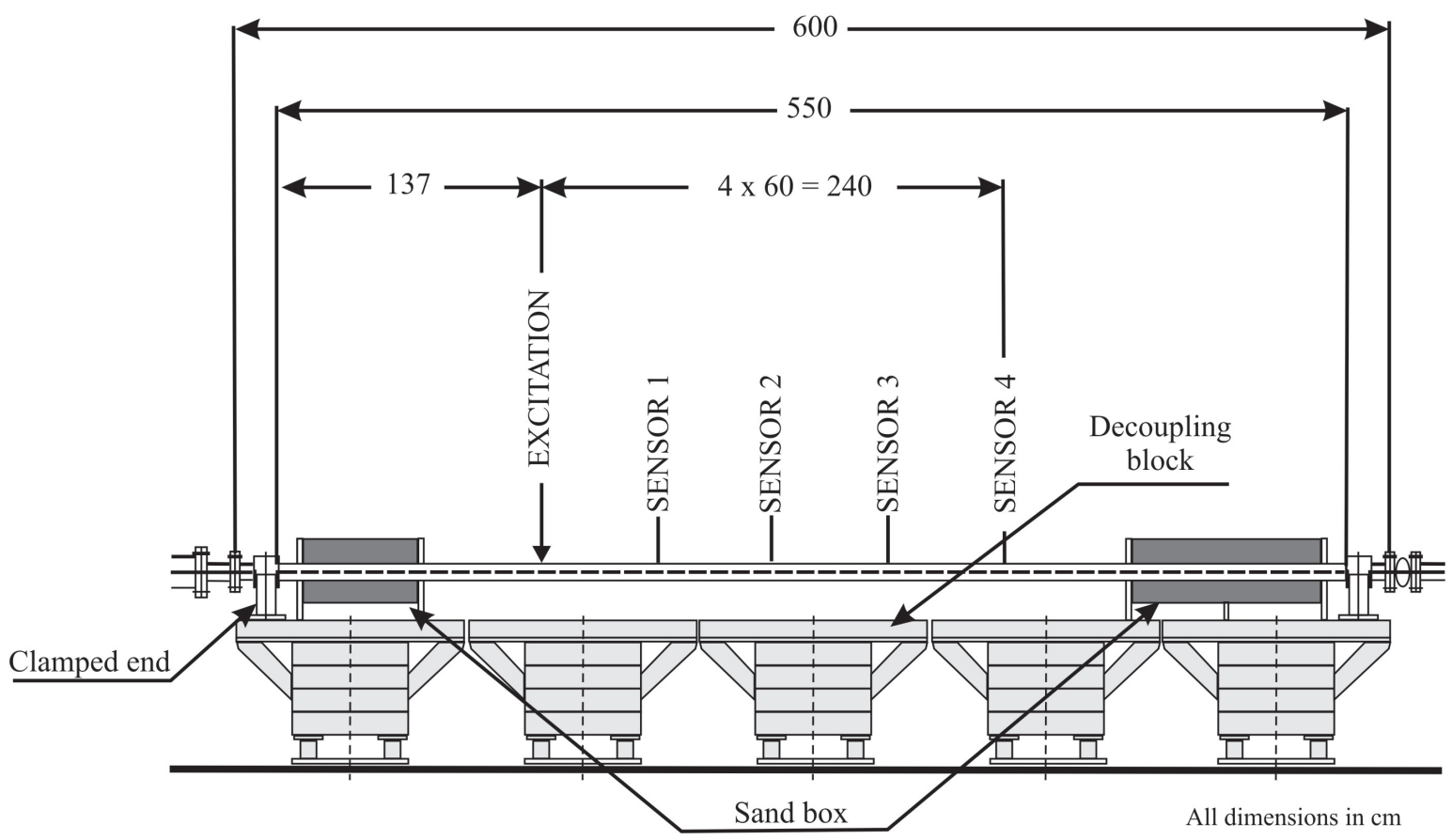

Figure 7: Experimental setup configuration

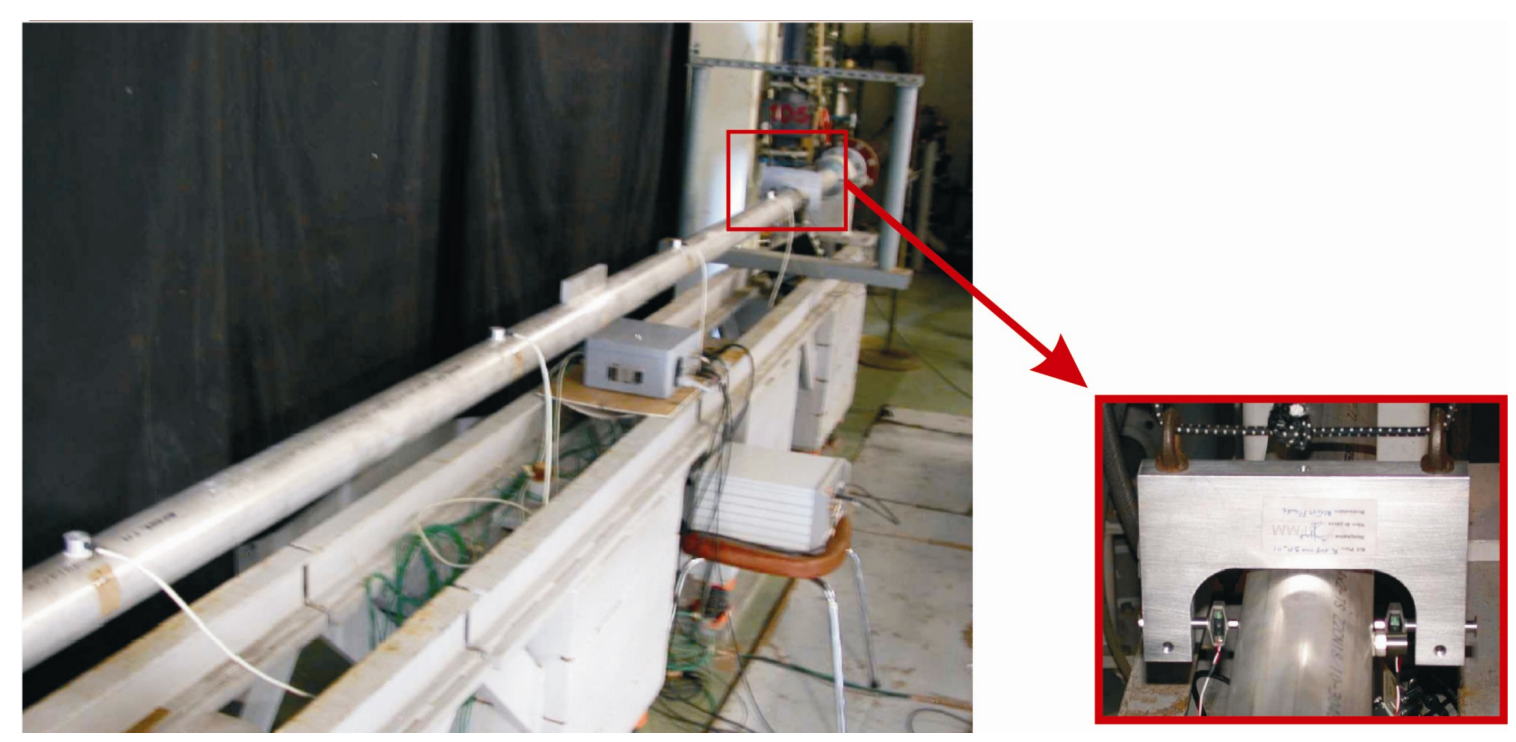

Figure 8: Experimental setup with excitation support 
The numerical model of this pipe section, developed by CIMNE, could not be calibrated. For this reason, the Finite Element Method model used can be observed in figure 9 and its characteristics are listed in table 2. The excitation signal was a sine wave with only one period and frequency of $773.75 \mathrm{~Hz}$. Four sensors were used as well. The pipe has been divided in 16 sections, and defects in each section were simulated by reducing thickness in $20 \%$ and $50 \%$ around the pipe (axisymmetrical reduction).
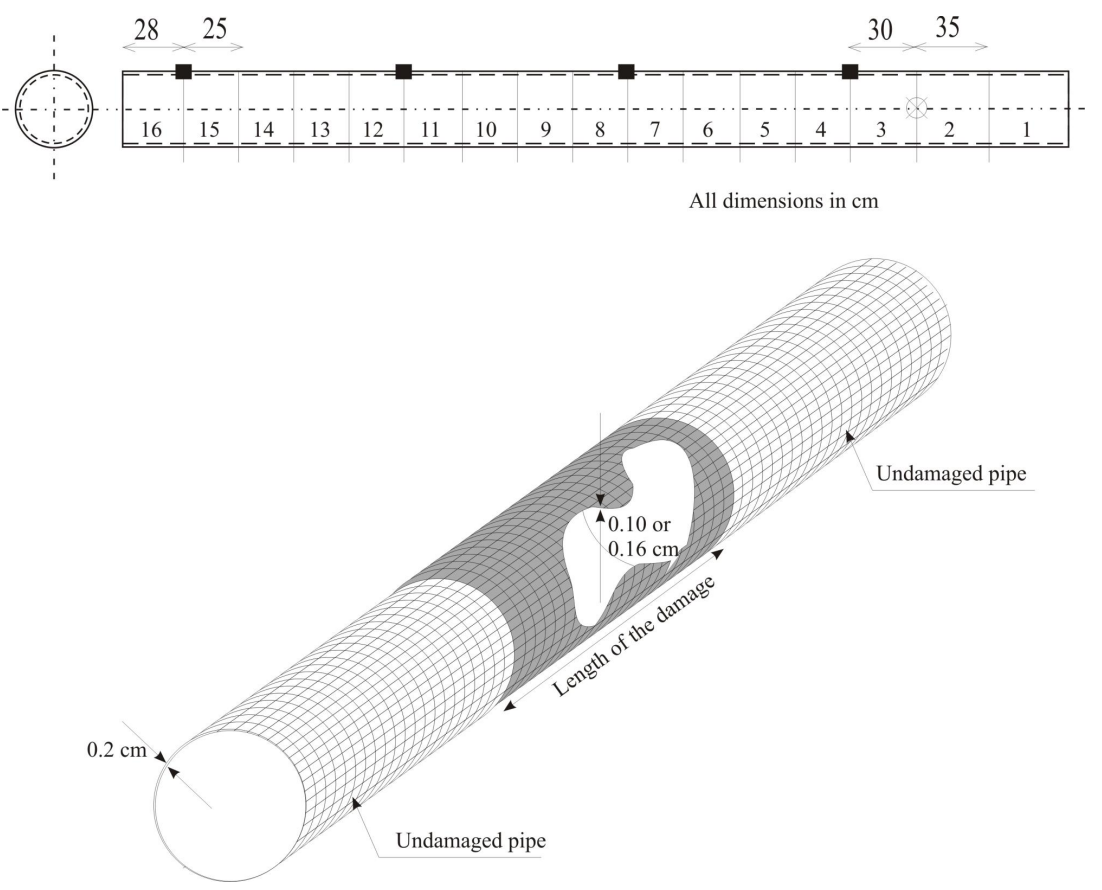

Figure 9: Pipe section model

Table 2: Model characteristics.

\begin{tabular}{lc}
\multicolumn{2}{c}{ Table 2: Model characteristics. } \\
\hline \hline & Density $\left(\mathrm{kg} / \mathrm{m}^{3}\right)$ \\
External radius & $4.2 \mathrm{~cm}$ \\
Inner radius & $4.0 \mathrm{~cm}$ \\
Thickness & $0.2 \mathrm{~cm}$ \\
Length & $4.28 \mathrm{~m}$ \\
Young's Modulus & $210 \mathrm{GPa}$ \\
Poisson's ratio & 0.28 \\
Density & $7800 \mathrm{~kg} / \mathrm{m}^{3}$ \\
Nodes & 202944 \\
Shell elements & 202880 \\
\hline \hline
\end{tabular}

\subsection{Long Pipe}

A $80 \mathrm{~m}$ pipe was provided by CEGELEC NDT. The experimental setup is shown in figure 10 . The material of this pipe was AE220 steel, its internal diameter was $30 \mathrm{~cm}$, its thickness $0.45 \mathrm{~cm}$ and its length $7887 \mathrm{~cm}$. It was excited using a 5-cycle Hanning windowed sine pulse with $474 \mathrm{~Hz}$ frequency, near its first radial-axis mode. The actuator, which can be seen from figure 11 is in quasi-static mode with a pre load of about $30 \mathrm{~N}$ (the preload is a glued $3 \mathrm{~kg}$ mass). Just one sensor is measuring dynamic response, it is located at a distance of $58 \mathrm{~m}$ from the actuator. Reversible defects have been performed. Three masses have been added in different positions. Due to the complexity of the structure a numerical model was not developed. 

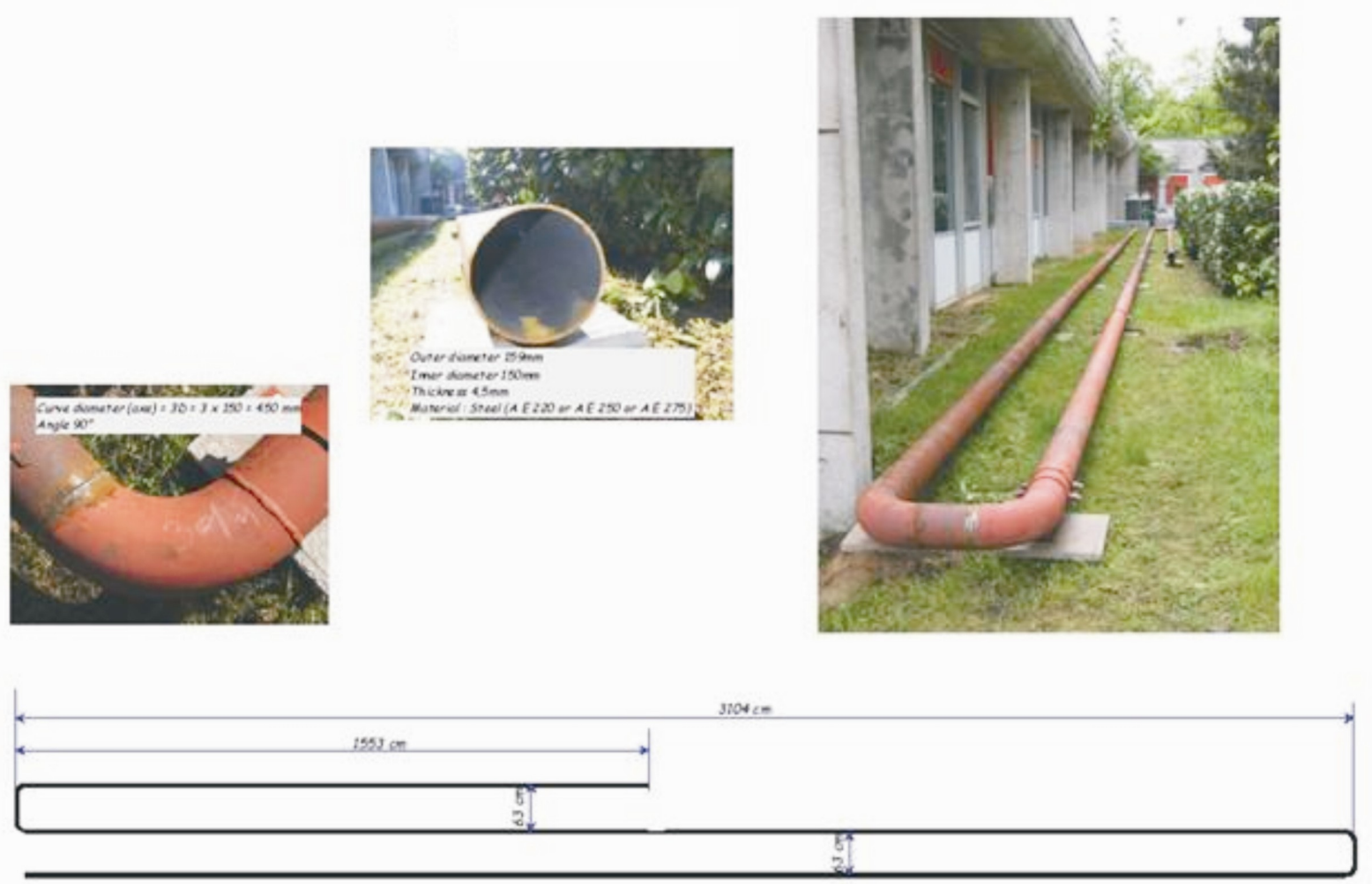

Figure 10: Experimental setup

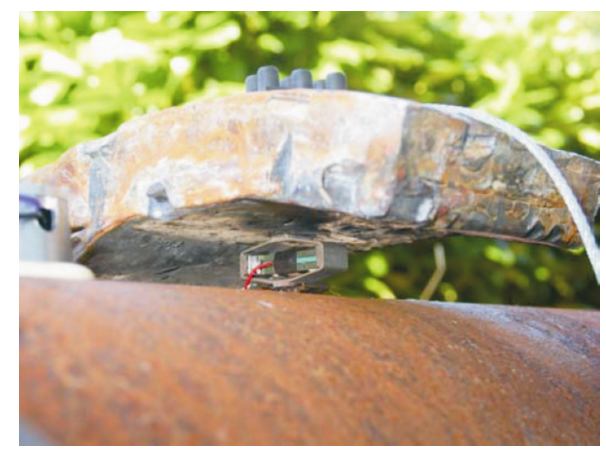

Figure 11: Excitation configuration

\subsection{Wing Flap Aircraft}

This structure, located in the facilities of the University of Sheffield, can be regarded as a small-scale version of part of a wingspan, with a leading edge and a trailing edge (see figure 12. The trailing edge was composed of aluminum skins with an aluminum honeycomb core, the leading edge of composite skins with a lightweight honeycomb core, and the central section of thin composite material. Unfortunately, due to the nature of the origin of the wing flap section, little is known about the specific materials. In this experiment, the excitation was produced by impacts. Nine sensors distributed over the surface detected strain responses. 


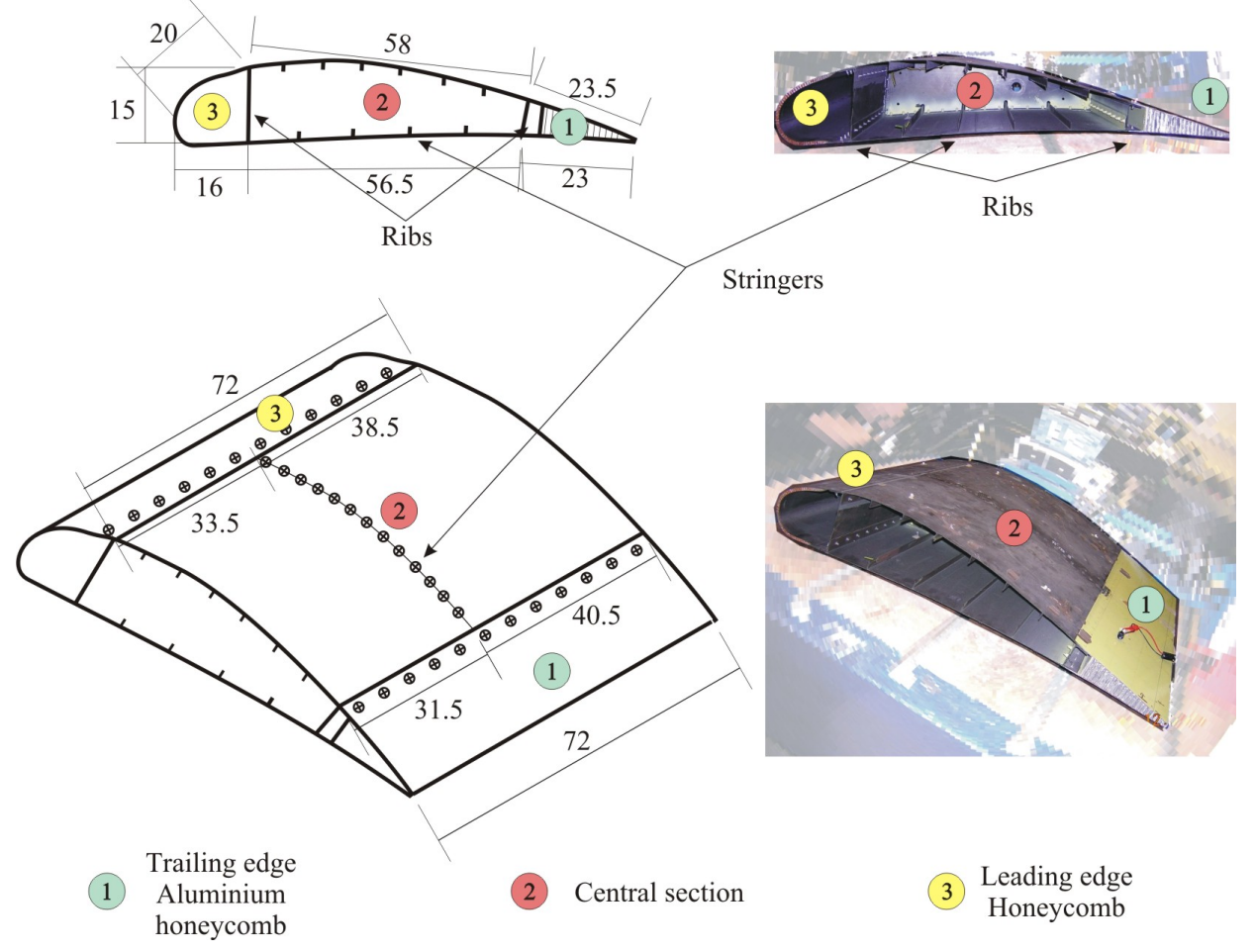

Figure 12: Schematic representation of the wing flap section. Dimensions in $\mathrm{cm}$.

\section{Overview}

This doctoral thesis does not follow a traditional structure. It is rather a compendium of articles; three of them have already been published, another one has been submitted for publication and a few others are in process of final revision. All deal with a common general theme: to detect and identify damages in structures. The papers are not necessarily reproduced in the same format as the published version. These are not presented in chronological order, nor do they have to be read in the order of arrangement, since each article can be read independently and has its own introduction and discussion.

The author of this thesis signs four papers as first author. The other two papers are comparison of two methodologies, so the paper has two principal authors, one of them being the developer of this thesis. All papers are signed (besides by the $\mathrm{PhD}$ candidate and the $\mathrm{PhD}$ adviser) by other researchers who have collaborated extensively, mainly in performing experiments, providing models and data, suggesting ideas and revising the writing.

Since the doctoral thesis is presented as a compendium or articles, this document is organized as follows:

- This introduction, which presents the papers and justifies the thematic unity of the thesis and the contribution of every co-author.

- Works already published, specifying authors, journal, and publication date, as well works in process of publication. Neither of them represent the published format.

- A global summary of results, an analysis of this summary and a discussion.

- Conclusions

- List of references used through this work. 
The first paper "A Hybrid Approach of Knowledge-Based Reasoning for Structural Assessment" can be considered the basis for the other papers. It was published in Smart Material and Structures journal, which has an Impact Factor of 1.522 according to Journal Citation Reports ${ }^{\circledR}$. It is classified in position 7 among 48 in the subject category of Instruments $\mathscr{G}$ Instrumentations. This paper describes in detail the methodology to detect and identify defects in structures. It is based on the analysis of changes in the vibration characteristics of the structure. This methodology can be used not only for structural assessment, but also for many other engineering problems. The methodology is explained by means of a numerical example of a cantilever truss structure which is excited with a predefined vibration signal, and the structural response is analyzed. Several defects are simulated, including the mass reduction in every element of the structure.

This methodology uses Case-Based Reasoning (CBR) as the diagnostic tool, and it is combined with other tools such as Wavelet Transform (WT) and a particular Artificial Neural Network (ANN): SelfOrganized Map (SOM). It describes the principles of CBR, its basic cycle that retains cases for use in the future by analogy. A case is defined for the minimal representation of the structural response to a given excitation and the defect of the structure. The casebase is the organization in memory of the set of cases in a coherent way. The casebase building includes a previous process of feature extraction from wavelet coefficients and using the central limit theorem. The retrieval process and the chosen strategy for selecting the amount of retrieved cases that should be used, is explained as well. Finally, the strategy to calculate the location, dimension and severity of the damage is presented.

This methodology has been also used to identify defects in an aluminum beam structure (see figures 4. 5 and 6). The numerical model of the structure was calibrated with the experimental structure and tested by Przemyslaw Kolakowski from SMART-TECH Centre (STC) Laboratory, in Warsaw, Poland. The casebase is build by means of damage simulations and tested with different damage simulations and a real defect on the structure. In both structures, the methodology performs satisfactorily in locating damage and assessing its size and severity.

The principal contribution of this paper can be assigned to two fields: i) in Artificial Intelligence (AI), the combination of another technique as the Self-Organizing Map into the Case-Based Reasoning methodology in order to improve the process of organizing and retrieving cases, and ii) in Structural Health Monitoring, the introduction of Case-Based Reasoning as an efficient tool for locating and identifying defects.

From this first paper, it was concluded that the methodology can be applied also in other problems in which there is previous knowledge of the structural behavior due to changes in the structure. One of these applications is the detection and localization of impacts. The structural damage is sudden and unpredictable. Here, the identification system is not active as in previous problems where actuators and sensors were present, and besides, the input energy was known. Now, the system is passive and there are only sensors, and the input energy is random, there is no knowledge about it, but it is known that the structure will have a reaction to the input. In this case, the impact produces strain waves that expand out over the whole surface and are perceived by sensors. This work have been performed with the collaboration of Prof José Rodellar, who contributed with knowledge, experience and suggestions in the way of developing and presenting the methodology

The second paper "Impact Damage Detection in Aircraft Composites Using Knowledge-Based Reasoning", is concerned with the location identification of impacts from signals acquired by sensors. It has been submitted to Structural Health Monitoring, an International Journal, and according to Journal Citation Reports ${ }^{\circledR}$ will be included in the journal in summer 2006. In general, the methodology described in the first paper was used, with the difficulty that the structure does not have only one sensor, it has nine. Therefore, nine casebases (one per sensor) are trained and built. When a new impact appears, the more similar cases are retrieved from the nine casebases. As an additional step, a strategy is developed for choosing which are the more relevant sensors. Finally, from the set of retrieved cases (joining all casebases), the location of the impact is determined by applying concepts of classical statistics.

The structure used in this study was a real part of a wing of a commercial aircraft as can be seen from figure 12, which is now located in the Smart Materials and Signals Processing Laboratory at Sheffield University. This structure is, obviously more complex than the one used in the first paper mentioned above. Due to its origin, little was known about the material characteristics and design, therefore, a model was not available. But, since an impact can be a nondestructive defect, many experiments have 
been performed. These consist in impacting the wing with a hammer in several known positions and collecting the sensed signals. Two sets of experiments were carried out in collaboration with professors Wieslaw Staszewski and Keith Worden. One experiment was performed following a grid and the other in random positions. The second set was used as a testing set in order to validate the methodology and determine its accuracy and reliability. The obtained results are very interesting, because the average error is small. Although the locations of several experiments was far from the real impact, many of them were located very close to it.

From the second paper emerges the idea of studying other techniques which can be used to i) reduce the dimensionality or extract the principal features of the signals and ii) organize the casebase into the CBR methodology. For this reason, the third paper, "Multivariate Statistics Process Control for Dimensionality Reduction in Structural Assessment" which will be submitted to IEEE Transactions on Pattern Analysis and Machine Intelligence (TPAMI), which has an Impact Factor of 4.352. It is classified in position 1 among 209 in the subject category of Engineering, Electrical $\&$ Electronic was performed. It reports on the performance of Multivariate Statistical Process Control (MSPC) to achieve this purpose. This tool or set of tools, which is used very often in chemometrics, is introduced into the Structural Health Monitoring field. Although some work has been previously performed, its strength and the huge advantages which can be used in damage identification or advanced signal processing in general have not yet been demonstrated. This work has been performed with the collaboration of Prof. Michel Verleysen, Dr Gurkan Sin and Magda Liliana Ruiz, a PhD student, who contributed with knowledge, experience, suggestions and new ideas concerning those techniques.

In this paper, the same structure and experiments used in the previous paper, are used. A brief, but quite sufficient explanation about linear MSPC techniques is presented. These include: Principal Component Analysis (PCA), Partial Least Square (PLS), and some extensions called Multiway PCA (MPCA) and Multiway PLS (MPLS). These extensions are very useful in systems that involve several sensors. MSPC techniques are used to reduce the dimensionality of the problem, for example from 140 samples by experiment to 10 or 20. Moreover, PCA, PLS and some nonlinear techniques like SelfOrganizing Maps (SOM) and Curvilinear Distance Analysis (CDA) are applied as a tool to organize cases in memory.

A total of 24 approaches have been performed, making use of several combinations of four techniques used to reduce dimensionality and four for organizing the casebases. Results show that the average error has improved (compared with results in the second paper); however, this reduction in errors is not too important. What is very important is to demonstrate that MSPC can be employed in SHM as well. And besides, the application of its extensions multiway drastically reduces the computation cost, because it does not need one casebase by sensor, and just one casebase is built for the whole system.

Usually in research, comparisons are performed either to highlight advantages and/or disadvantages of techniques (or methodologies) or to show that a new one has the same or better performance than the another well-known one. In the intention of highlighting advantages and disadvantages of two completely different methodologies, papers 4 and 5 which are titled "Two Approaches to Structural Damage Identification: Model Updating versus Soft Computing" and "Comparison of Two Software Tools for Damage Identification: Gradient-based vs. Case-Based Approach" have been published. The first one, in Journal of Intelligent Material Systems and Structures, which has an Impact Factor of 0.647. It is classified in position 96 among 177 in the subject category of Material Science, Multidisciplinary. The second paper was published in Key Engineering Materials, and its Impact Factor is 0.278. It is classified in position 15 among 25 in the subject category of Material Science, Composites.

These papers compare the methodology developed and presented by the author throughout this thesis, which belongs to the class of soft-computing methods, and another methodology based on the Virtual Distortion Method developed by Przemyslaw Kolakowski from SMART-TECH Centre (STC). The latter is included into the class of model-updating methods and it uses gradient-based optimization techniques.

Both methods were developed for low-frequency application on the basis of the research project titled "PIEZODIAGNOSTICS: Smart Structural Diagnostics using Piezo-Generated Elastic Waves". The paper gives an overview of both methodologies. Numerical examples of an aluminum beam and the model calibration are given. For general purposes, three cases of damage were considered. The comparison was performed considering computational cost and effectiveness in identifying the damage. 
The last paper, titled "Non-Destructive Testing for Assessing Structures by Using Soft-Computing", summarizes the main results obtained on the basis of the project PIEZODIAGNOSTICS regarding to damage identification using the methodology presented in this thesis. In this project, the methodology was tested, besides the beam (figures 4, 5 and 6), in a pipe section of $4.28 \mathrm{~m}$ (see figures 78 and 9 ) and its numerical model and in a long pipe of $80 \mathrm{~m}$ (shown in figure 10). In order not to produce irreversible damages to the structures, it was decided that the damages to be generated and identified would be added masses with different shapes and weights. In this way, these defects could be considered as the inverse of the corrosion defect (mass reduction).

The work presented here can be summarized as follows: i) a general methodology to assess structures, ii) the application of this methodology on several structures (beam, pipe section, long pipe and wing aircraft) and identification of different types of defect (corrosion, mass reduction, added masses and impact loads), iii) a study of several techniques to combine with the main methodology in order to reduce dimensionality of the problem and organize previous knowledge, and iv) a comparison with another technique based on model updating.

Analysis results and discussion are presented as well. A global summary of results is shown and a comparison of the case studies is performed. Advantages, limitations and suggestions are given. Finally, the thesis is concluded and the main contributions of the thesis are assessed. 


\title{
Paper 1: \\ A Hybrid Approach of Knowledge-Based Reasoning for Structural Assessment
}

\author{
Luis Eduardo Mujica
}

Department of Electronics, Computer Science and Automatic Control.

University of Girona (UdG), 17071 EPS-PIV Campus Montilivi, Girona, Spain

\section{Josep Vehí}

Department of Electronics, Computer Science and Automatic Control.

University of Girona (UdG), 17071 EPS-PIV Campus Montilivi, Girona, Spain

\section{José Rodellar}

Department of Applied Mathematic III

Technical University of Catalonia (UPC), 08034 Campus Nord, Barcelona, Spain

\section{Przemyslaw Kolakowski}

Institute of Fundamental Technological Research

Polish Academy of Sciences, Świętokrzyska 21, 00-049 Warszawa, Poland

\begin{abstract}
A hybrid reasoning system is developed for damage assessment of structures. The system combines the use of a model of the structure with a knowledge-based reasoning scheme to evaluate if damage is present, its severity (severity and dimension) and its location. Using a given model (or several models), the structural dynamic responses to given excitations are simulated in the presence of different forms of damage. In a "learning mode" an initial casebase is created with the principal features of these damage responses. When the system is working in its operating mode, data acquired by sensors are used to perform a diagnosis by analogy with the cases stored in the casebase, reusing and adapting old situations. Whenever a new situation is detected, it is retained in the casebase to update the available information. This paper describes the methodology and how the system is built and tuned to be ready for operation. This is illustrated by a numerical example of a cantilever truss structure and tested numerically and experimentally with a beam structure. Conclusions are presented with the emphasis on the advantages of using knowledge-based systems for structural assessment.
\end{abstract}

\section{Published in:}

Journal: Smart Materials and Structures

Publisher: Institute of Physics Publishing

Volume 14, Number 6, December 2005, Pages 1554-1562
ISSN: 0964-1726

Impact Factor: 1.522

Online at: stacks.iop.org/SMS/14/1554 



\title{
Paper 2: \\ Impact Damage Detection in Aircraft Composites Using Knowledge-Based Reasoning
}

\section{Luis Eduardo Mujica}

Department of Electronics, Computer Science and Automatic Control.

University of Girona (UdG), 17071 EPS-PIV Campus Montilivi, Girona, Spain

Josep Vehí

Department of Electronics, Computer Science and Automatic Control.

University of Girona (UdG), 17071 EPS-PIV Campus Montilivi, Girona, Spain

Wieslaw J. Staszewski

Department of Mechanical Engineering

University of Sheffield, Mappin Street S1 3JD Sheffield, United Kingdom

\section{Keith Worden}

Department of Mechanical Engineering

University of Sheffield, Mappin Street S1 3JD Sheffield, United Kingdom

\begin{abstract}
A hybrid reasoning methodology is applied to a complex aerospace structure, its effectiveness is assessed in identifying and locating the position of impacts. Part of a commercial aircraft wing flap is impacted and time varying strain response data from the structure are sensed using passive piezoceramic sensors.

This structure can be regarded as a small scale version of part of a wing span with the corresponding features being a leading edge and trailing edge. The trailing edge is composed of aluminium skins with an aluminium honeycomb core, the leading edge of composite skins with a light weight honeycomb core and the central section of thin composite material. Nine sensors, to detect time varying strain response data, are distributed over the surface of the flap; two on the leading edge, two on the trailing edge and five in the central section.

The methodology combines the use of: i) Case Based Reasoning; in a "learning mode", an initial casebase is created with the principal features of the impact responses. When the system is working in an "operating mode", the data acquired by sensors are used to perform a diagnosis by analogy with the cases stored in the casebase: reusing and adapting old situations. ii) The Wavelet Transform is used to extract principal features of a signal providing information about the impact locations. iii) Self Organizing Maps are trained as a classification tool in order to organize the old cases in memory with the purpose of speeding up the reasoning process. Finally, when old similar cases are retrieved, the impact location is obtained directly from heuristic considerations.
\end{abstract}

\section{Submitted to:}

Journal: Structural Health Monitoring, An International Journal Publisher: SAGE Publications

ISSN: $1475-9217$

Impact Factor: New Journal 



\title{
Paper 3:
}

\section{Multivariate Statistics Process Control for Dimensionality Reduction in Structural Assessment}

\section{Luis Eduardo Mujica}

Department of Electronics, Computer Science and Automatic Control.

University of Girona (UdG), 17071 EPS-PIV Campus Montilivi, Girona, Spain

\section{Josep Vehí}

Department of Electronics, Computer Science and Automatic Control.

University of Girona (UdG), 17071 EPS-PIV Campus Montilivi, Girona, Spain

\section{Magda L. Ruiz}

Department of Electronics, Computer Science and Automatic Control.

University of Girona (UdG), 17071 EPS-PIV Campus Montilivi, Girona, Spain

Michel Verleysen

Electricity Department

Université Catholique de Louvain, Place du Levant, B-1348 Louvain-la-Neuve, Belgium

\section{Wieslaw J. Staszewski}

Department of Mechanical Engineering

University of Sheffield, Mappin Street S1 3JD Sheffield, United Kingdom

\section{Keith Worden}

Department of Mechanical Engineering

University of Sheffield, Mappin Street S1 3JD Sheffield, United Kingdom

\begin{abstract}
This paper presents advantages of using techniques like Principal Components Analysis (PCA), Partial Least Square (PLS) and some extensions called Multiway PCA (MPCA) and Multiway PLS (MPLS) for reducing dimensionality in damage identification problem, in particular, detecting and locating impacts in a part of a commercial aircraft wing flap. It is shown that applying MPCA and MPLS is convenient in systems which many sensors are monitoring the structures, because the reciprocal relation between signals is considered. The methodology used for detecting and locating the impact uses the philosophy of Case Based Reasoning (CBR). Non linear techniques like Self Organizing Maps (SOM) and Curvilinear Distance Analysis (CDA) are combined into the CBR methodology to organize previous knowledge in memory. 24 approaches combining those techniques have been performed. Results from all of them are presented, compared and discussed.
\end{abstract}


Paper 3: Multivariate Statistics Process Control for Dimensionality Reduction in Structural

\section{To be submitted to:}

Journal: IEEE Transactions on Pattern Analysis and Machine Intelligence Publisher: IEEE Computer Society

ISSN: 0162-8828

Impact Factor: 4.352 


\title{
Paper 4:
}

\section{Two Approaches to Structural Damage Identification: Model Updating versus Soft Computing}

\section{Przemyslaw Kolakowski}

Institute of Fundamental Technological Research

Polish Academy of Sciences, Świętokrzyska 21, 00-049 Warszawa, Poland

\section{Luis Eduardo Mujica}

Department of Electronics, Computer Science and Automatic Control.

University of Girona (UdG), 17071 EPS-PIV Campus Montilivi, Girona, Spain

\section{Josep Vehí}

Department of Electronics, Computer Science and Automatic Control.

University of Girona (UdG), 17071 EPS-PIV Campus Montilivi, Girona, Spain

\begin{abstract}
This article presents two approaches for structural damage identification, each based on a different philosophy. The virtual distortion method (VDM) is a model-updating method of damage assessment, utilizing gradient-based optimization techniques to solve the resulting inverse dynamic problem in the time domain. Case-based reasoning (CBR) is a softcomputing method utilizing wavelet transformation for signal processing and neural networks for training a base of damage cases to use for retrieving a similar relevant case. Advantages and drawbacks of each approach are discussed. Successful calibration of a numerical model from experiments has been shown as a sin equa non for the VDM approach. A numerical example of a beam is presented including a demonstration of the complexity of the inverse problem. Qualitative and quantitative comparisons between the two approaches are made.
\end{abstract}

\section{Published in:}

Journal: Journal of Intelligent Material Systems and Structures Publisher: SAGE Publications

ISSN: $1045-389 \mathrm{X}$

Volume 17, Number 1, January 2006, Pages 63-79

Impact Factor: 0.647

Online at: jim.sagepub.com 



\title{
Paper 5:
}

\section{Comparison of Two Software Tools for Damage Identification: Gradient-based vs. Case-Based Approach}

\section{Przemyslaw Kolakowski}

Institute of Fundamental Technological Research

Polish Academy of Sciences, Świętokrzyska 21, 00-049 Warszawa, Poland

\section{Luis Eduardo Mujica}

Department of Electronics, Computer Science and Automatic Control.

University of Girona (UdG), 17071 EPS-PIV Campus Montilivi, Girona, Spain

\section{Josep Vehí}

Department of Electronics, Computer Science and Automatic Control.

University of Girona (UdG), 17071 EPS-PIV Campus Montilivi, Girona, Spain

\begin{abstract}
Two alternative software tools for damage identification are presented. The first tool, developed on the basis of the Virtual Distortion Method (VDM), takes advantage of an analytical formulation of the damage identification problem. Consequently, gradient-based optimization method is applied to solve the resulting dynamic inverse problem in time domain. Finite element model of the structure is necessary for the VDM approach. The second tool utilizes the Case-Based Reasoning (CBR) for damage identification. This method consists in i) extracting principal features of the response signal by wavelet transform, ii) creating a base of representative damage cases, iii) organizing and training the base by neural networks, and finally iv) retrieving and adapting a new case (possible damage) by similarity criteria. Basic description of both approaches is given. A comparison of numerical effectiveness, in terms of accuracy and computational time, is provided for a simple beam structure. Advantages and weaknesses of each approach are highlighted.
\end{abstract}

\section{Published in:}

Journal: Key Engineering Materials Publisher: Trans Tech Publications Volume 293-294, July 2005, Pages 103-110
ISSN: $1013-9826$

Impact Factor: 0.278

Online at: www.scientific.net 



\title{
Paper 6:
}

\section{Non-Destructive Testing for Assessing Structures by Using Soft-Computing}

\section{Authors}

\section{Luis Eduardo Mujica}

Department of Electronics, Computer Science and Automatic Control.

University of Girona (UdG), 17071 EPS-PIV Campus Montilivi, Girona, Spain

\section{Josep Vehí}

Department of Electronics, Computer Science and Automatic Control.

University of Girona (UdG), 17071 EPS-PIV Campus Montilivi, Girona, Spain

\section{José Rodellar}

Department of Applied Mathematic III

Technical University of Catalonia (UPC), 08034 Campus Nord, Barcelona, Spain

\begin{abstract}
A hybrid system which combines Self Organizing Maps and Case Based Reasoning is presented and apply to Structural Assessment. Self Organizing Maps are trained as a classification tool in order to organize the old cases in memory with the purpose of speeding up the Case Based Reasoning process. Three real structures have been used: An aluminium beam, a pipe section and a long pipe.
\end{abstract}

In revision process 



\section{Results and Discussion}

The methodology developed through this doctoral thesis to assess structures using Knowledge-Based Reasoning has been applied in the following case studies:

- Detecting, locating and evaluating defects produced by corrosion or mass reduction in numerical examples (cantilever, beam and pipe section) and experimental structures, such as a beam (reported in papers $1,4,5$ and 6$)$.

Because generating simulations of the structural response with defects carries a high computational cost and implementing several irreversible defects in any structure is expensive, the methodology has been tested using a few experiments which represent a set of defects whose identification is desirable. For this reason, using these structures, the methodology could not be evaluated in a quantitative way, calculating for instance average errors in the identification process. Instead, qualitative evaluation was performed.

The position of the damage is presented in terms of probability. This means determining in which element of the structure there is a higher probability of finding the damage. The size and severity of the damage (evaluation of the damage) were calculated using a weighted average considering distances in retrieve steps.

The methodology locates quickly the damage in all three cases (cantilever, beam and pipe section), and its evaluation is sufficient for industrial needs. In some scenarios (i.e. three simultaneous damages in three different locations using the beam structure), the methodology results were not very accurate in the evaluation of the damage but its localization was correct. Trying to identify a defect in an experiment when the casebase was trained with numerical simulations (even if the numerical model was not correctly calibrated) produced an acceptable localization, although not an accurate evaluation. That is shown using the beam experiment.

- Detecting, locating and evaluating defects produced by adding masses in a pipe section and in a long pipe (reported in paper 6).

Due to calibration problems between the pipe section and its Finite Element Method (FEM) model, the impossibility of having a numerical model for the long pipe, and besides the impracticability of performing reversible defects in those structures, this study has been carried out using only experiments over the structures, and generating defects by adding different shapes of masses in different locations. The methodology was tested adding a different mass in several locations. All defects were located very accurately, but the estimation of the added mass in some cases was not correct. The disadvantage of these case studies is the relatively small number of performed experiments (46 in pipe section and 151 in the long pipe)

- Detecting and locating impacts in a part of an aircraft wing (reported in papers 2 and 3).

In this case study, impacting the wing, registering the propagated waves and repeating the process again do not represent any high cost either computational or economical. Consequently, two set of experiments have been performed: one of them to train the methodology and the other one for testing it. From this set of tests, besides the qualitative evaluation, a quantitative evaluation can be presented as well.

The structure had nine sensors located over the surface of the wing span. In paper 2, the signals by each sensor were analyzed separately. In addition, it studied the possibility of using i) only the 
more relevant sensors, considering distances which represent similarity in the retrieve process, ii) sensors closest to the impact (previously, the section where impact was carried out was found using the main methodology and all sensors) and, iii) all sensors. Results showed that the average radial error in locating the impacts is achieved considering signals from all sensors. That error is 59.39 $\mathrm{mm}$. In paper 3, signals from the whole set of sensors were analyzed considering the relationship between them. The obtained average error in most approaches was around $50 \mathrm{~mm}$. The reduction of the error is approximately $15 \%$.

On the other hand, in paper 2, three classical statistical concepts (median, mean and weight mean) were used to calculate the location of the impact from retrieved cases in the adaption step. Given the results, it can be deduced that the localization of the impact is more accurate using the median concept, since it reduces outliers in data. Experiment by experiment is analyzed as well. From the results it can be seen that most of them are located very accurately, at less than $25 \mathrm{~mm}$, but in a few cases the average error was too high, greater than $100 \mathrm{~mm}$. Those cases were studied separately, but no relationship or explanation was found.

The former results are very attractive for the Structural Health Monitoring community due the high accuracy and complexity of the structure, since that the wing is composed of three perfectly distinguishable sections, where the material and design are different and unknown.

On the other hand, the introduction of new techniques into the Case -Based Reasoning methodology and specially into a vibration-based damage detection problem, opens even more possibilities for solving problems in the Structural Health Monitoring field and for solving many other engineering problems. Linear techniques such as Principal Component Analysis (PCA), Partial Least Square (PLS) and its extensions, as well as nonlinear techniques like Curvilinear Distance Analysis (CDA) and Self-Organizing Maps (SOM) produce a performance benefit. A total of 192 combinations of these techniques have been performed and tested using experiments carried out in the span wing aircraft. Although with some of these approaches, the average radial error was a little greater than for the others and than the results presented in paper 2, their values are acceptable. Neither of the possible combinations (approaches) has an average radial error greater than $80 \mathrm{~mm}$. The three sections of the wing have been analyzed separately, concluding that the leading edge section has the least average error (it does not exceed $40 \mathrm{~mm}$ using any combination). That is because more experiments were performed in this section.

As another point of view, this study revealed that the main advantage of using these techniques is to reduce dimensionality if the system has a large amount of sensors measuring the same effect in different locations. That reduction of data, and therefore of time, is the most important contribution.

The application of the this hybrid Knowledge-Case Reasoning methodology for detecting, locating and evaluating defects or damages in structures has presented the following advantages:

- If a numerical model of the structure is available, it can be used for building the casebase of defects. In addition, when new experimental defects are produced and identified, it may be retained into the casebase, improving its robustness against model errors.

- In some cases, just one numerical model is not sufficient to interpret the behavior of the structure. This methodology allows the use of several and/or simultaneous models for building the casebase.

- If a numerical model of the structure is not available, but nondestructive experiments such as light impacts or mass addition can be achieved, the casebase may be built using those experiments. In the same way, a new experiment is retained into the casebase.

- In the Structural Health Monitoring field, it is very often the employment of many sensors for recording several variables or the structural response in different locations. All this information can be processed either separately or by analyzing its correlation, for extracting features and reducing its dimension. 
However, by means of the applications in those case studies, some limitations have been found and should be kept in mind if someone wants to use the methodology.

- In order to build an efficient casebase, it is necessary to generate a set of experiments that it is a good representation of the defects to be detected. That is shown in papers 4 and 5, where this methodology is compared with VDM methodology. There, identifying three different defects is the goal, and it requires building three different casebases. One casebase only is not applicable. However, in the problem of detecting and locating impacts over the wing, having experiments over the entire surface is enough.

- Generating the set of cases by means of either damage simulations or nondestructive tests requires a high computational and/or experimental cost. However, it is very important to emphasize that this process has to be carried out just once. Building the casebase, extracting features or reducing dimensionality is a very fast step. Once the system is trained, using any proposed technique (SOM, CDA, PCA or PLS), the retrieving and adaptation process to identify the damage is almost immediate. 


\section{Conclusions and Future Research}

\section{Conclusions}

This thesis presents a methodology for assessing structures in civil, mechanical and aerospace engineering. The work performed was focused on vibration analysis, signal processing and damage identification using Knowledge-Based Reasoning. This methodology allows detecting and identifying defects in structures using the principle of Case-Based Reasoning, and it is performed from vibration measurements which can be generated in either a controlled way or randomly, suddenly and unknowingly. Case-Based Reasoning methodology has become known in Structural Health Monitoring and solves a problem by focusing on the idea that "similar problems have similar solutions", which translated into a Structural Health Monitoring problem, becomes "similar defects have similar dynamic response".

The methodology has been validated in simulated and laboratory applications, demonstrating its high accuracy in detecting and locating damages and its satisfactory accuracy for industrial applications in evaluating dimension and severity of the damage. These case studies have a high diversity of models (FEM and VDM), excitations (sine pulse, windowed sine or known-impact) and damages (mass reduction, added mass and impact loads). The results show a high adaptability regardless the model, kind of damage and/or excitation signal.

On the other hand, structural engineering diagnostics are often complex due to the large number of possible models for interpreting structural behavior. For example, in a bridge, one model is the best for simulating cracks at the support, but a different model is the best for simulating damage in the midspan of the bridge. This methodology permits simultaneous use of several models in building the casebase.

In general, if the numerical model of the structure exists and it is calibrated, it can be used to build the casebase. However, if it does not exist, the casebase can be loaded with nondestructive experiments. In both circumstances, the casebase can be updated while retaining already-identified experiments, improving the robustness of the methodology against error in the model.

Choosing the adequate casebase is a task which must be done with care, because it must be loaded with defects that are expected to take place. In theory, the casebase can be loaded with a very large number of cases, but in practice, physical limitations for storage and high computational and/or economical cost are present. In some of the case studies used for validation, many experiments and/or simulations were performed. In others, few experiments and/or simulations could be carried out. In all cases, the accuracy was high, because the kind of damage needing to be identified corresponded to damages in the casebase. It means that if it is desirable to detect damage with a dimension of less than $30 \mathrm{~cm}$ in the pipe section, it is necessary to simulate structural responses with damages of this dimension. It is not applicable to identify defects not considered to belong to the casebase. For instance, it is not possible to identify three simultaneous damages in a beam using simulations of only one damage.

Once the casebase has been properly chosen, the more experiments and/or simulations performed, the higher the accuracy of the methodology. This was demonstrated in the wing flap case study; in one of its sections (leading edge) more experiments were carried out, and the errors themselves were smaller.

Current methodologies for damage identification require a high computational cost every time a new damage appears. This limits their applicability in real time. The developed methodology, which consists of two steps, building the casebase and retrieving and adapting for damage identification, is computational expensive for building the casebase because it demands numerous inputs by simulations and/or experiments. But, once this casebase is built, identification of a new episode of damage is almost immediate. Therefore, it is reasonable to conclude that this methodology can be applied to assess structures in real time. 
The performance of Case-Based Reasoning is improved by integrating other techniques for reducing the dimensionality of the problem and organizing the previous knowledge in memory. The efficiency of using Multivariate Statistical Process Control (MSPC) techniques, nonlinear techniques as Self-Organizing Maps (SOM) and Curvilinear Distance Analysis (CDA), to process signals in Structural Health Monitoring has been illustrated by means of many performed approaches. It has been shown that the application of PCA, PLS, SOM and CDA for case retrieving is very effective, however, the nonlinear techniques (SOM and CDA) require a greater computational effort than the linear techniques (PCA and PLS).

If the structure is monitored by using several sensors, the correlation between the sensors must be considered. In this thesis, it is shown that "Multiway" extensions of PCA and PLS are efficient techniques to study reciprocal relations between signals. In this way, the dimension of the problem (with many sensors) can be reduced to the dimension of a problem with only one sensor, and the computation time is therefore reduced drastically.

\section{Main Contribution}

The absence of numerical models and/or the difficulty for calibrating them with mechanical, civil and/or aerospace structures justifies the development of a methodology for detecting and identifying defects, based on previous knowledge of the structure. Therefore, the main contribution of this thesis is the development of a hybrid methodology using Case-Based Reasoning and other techniques for evaluating damages in structures. This methodology can be used regardless whether the numerical model exists. The evaluation includes finding whether damage is present, defining its location, its dimension and its severity.

On the other hand, the first appearance of techniques and methodologies (showing their feasibility), heretofore unknown in the Structural Health Monitoring field, has been appreciated by the community. These tools are: Case-Based Reasoning, Multiway Partial Least Square, Multiway Principal Component Analysis and Curvilinear Distance Analysis.

\section{Future Research}

This thesis is intended to contribute to the development of new techniques for identifying damages in structures based on vibration analysis. Nevertheless, this work is only a particular approach to the wide field of Structural Health Monitoring. Future research is certainly needed to obtain a robust, automatic, generally applicable monitoring system. The immediate future work will be focused on the following subjects:

\subsection{Dimensionality Reduction}

In this work some techniques used very often in other engineering problems have been successfully applied in Structural Health Monitoring. A more in-depth analysis of this techniques should be carried out and in this way, other of their characteristics can become useful. On the other hand, there is also a need to explore other techniques to reduce the dimensionality, such as, for instance, mutual information for the selection of relevant variables.

\subsection{Numerical Modeling}

The effectiveness of the methodology developed in this work, using the numerical model of the structure to built the casebase and experiments for its validation, has been shown using only the aluminum beam case study. The other structure case studies lack an appropriate numerical model. This topic can be improved, structures with a numerical model sufficiently calibrated could provide diagnostics with higher accuracy. 


\subsection{Reliability and Risk Analysis}

The methodology presented in this work, reaches up level 3 in damage identification, that is, quantification of the severity of the damage [Ryt93]. A study of extension of this methodology to reach level 4 can be performed. This level, prediction of the remaining service life of the structure, is generally associated with fatigue-life analysis or with reliability and risk analysis.

\subsection{Application in Real-Time Monitoring}

There is scope in which to apply this methodology and/or its variations for detecting, locating and identifying in real time (a few milliseconds) impacts loads in other available structures (e.g. wing aircraft, antennas, smart structures).

\section{Contributions to Relevant Conferences and Workshops}

The development of this work has been disclosed and discussed, in addition to the articles presented in this thesis, in the following international conferences and workshops. The subjects of this events are Structural Health Monitoring, Damage Assessment in Structures and, Soft Computing and Artificial Intelligence.

Multivariate Statistics Process Control for Dimensionality Reduction in Structural Health Monitoring

Luis Eduardo Mujica and Josep Vehi

Accepted in Third European Workshop on Structural Health Monitoring

Granada - Spain, Jul 07, 2006

A hybrid system combining Self-Organizing Maps with Case Based Reasoning in Structural Assessment

Luis Eduardo Mujica, Josep Vehí and José Rodellar

Artificial Intelligence Research and Development. Frontiers in in Artificial Intelligence and Applications Vuitè Congrés Català d'Intelůligència Artificial - CCIA'2005,

Alguer - Italy, Oct 28, 2005 vol. 131 pag. 173 - 180

Comparison of Two Software Tools for Damage Identification: Gradient-based vs. Casebased Approach

Przemyslaw Kolakowski, Luis E. Mujica, Josep Vehí

DAMAS 2005 6th International Conference on Damage Assessment of Structures,

Gdansk - Poland, Jul 6, 2005 vol. 293 pag. 103 - 110

Detección de impactos mediante Razonamiento Basado en Conocimiento: Aplicación a una sección de ala de avión (in Spanish)

Luis Eduardo Mujica, Josep Vehí and José Rodellar

Actas de SAICA 2005 Seminario de Aplicaciones Industriales de Control Avanzado

Madrid - Spain, Oct 20, 2005 pag. 197 - 206

Impact Damage Detection In Aircraft Composites Using Knowledge-Based Reasoning Luis Eduardo Mujica, Josep Vehi, Wieslaw Staszewski and Keith Worden

Structural Health Monitoring 2005. Advanced and Challenges for Implementation

5th International Workshop on Structural Health Monitoring 2005

Stanford - CA, USA Sep 14, 2005 pag. 487 - 294

Hybrid knowledge based reasoning approach for structural assessment Luis Eduardo Mujica, Josep Vehí, José Rodellar, Oscar García, Przemyslaw Kolakowski

2nd European Workshop on Structural Health Monitoring

Munich - Germany, Jul 07, 2004 pag. 591 - 598 
Damage Identification by Case Based Reasoning

Luis Eduardo Mujica, Josep Vehi, José Rodellar, Przemyslaw Kolakowski

AMAS Conference Proceedings AMAS/ECCOMAS/STC

Workshop on Smart Materials and Structures

Jadwisin - Poland, Sep 05, 2003 pag. 261 - 269

Damage Identification by using Soft Computing Techniques

Luis Eduardo Mujica, Josep Vehi

Workshop on Soft Computing and Complex Systems.

Coimbra - Portugal, Jun 23, 2003

Damage Identification using Case Based Reasoning and Self Organizing Maps

Luis Eduardo Mujica, Josep Vehi

Third European Symposium on Intelligent Technologies, Hybrid Systems and their implementation on Smart Adaptive Systems.

Oulu - Finland, Jul 12, 2003

\section{Book contribution}

Experiences in exploiting data: Selected problems in application domains

Meléndez J., Colomer J. , Lopez B., Vehi J., Pous C., Ruiz M.L., Mujica L.E.

Tendencias de la Mineria de Datos en España. Red Española de Mineria de Datos y Aprendizaje (TIC2002-11124-E)

2004 vol. 1 pag. 59 - 70 


\section{Bibliography}

[Abr98] S. Abrate. Impact on Composite Structures. Cambridge University Press, 1998.

[AGH01] M.A. Akgun, J.H. Garcelon, and R.T. Haftka. Fast exact linear and non-linear structural reanalysis and the sherman-morrison-woodbury formulas. International Journal for Numerical Methods in Engineering, 50:1587-1606, 2001.

[AP94] A. Aamodt and E. Plaza. Case-Based Reasoning: Foundational issues, methodological variations, and system approaches. Artificial Intelligence Communications, 7(1):39-59, 1994.

[AV98] M.F.A. Azeez and A.F. Vakakis. Proper orthogonal decomposition of a class of vibroimpact oscillations. Journal of Sound and Vibration, 240:859-889, 1998.

[BG03] P. De Boe and J.C. Golinval. Principal component analysis of piezo-sensor array for damage localization. Structural Health Monitoring: An International Journal, 2(2):137-144, 2003.

[BL96] N. K. Bose and P. Liang. Neural Network Fundamentals With Graphs, Algorithms, 6 Applications. McGraw-Hill, 1996.

[BSCT01] C. Biemans, W.J. Staszewski, C. Boller C, and G.R. Tomlinson. Crack detection in metallic structures using broadband excitation of acousto-ultrasonics. Journal of Intelligent Material Systems and Structures, 12(8):589-597, 2001.

$\left[\mathrm{BSW}^{+} 00\right]$ C. Boller, W.J. Staszewski, K. Worden, G. Manson, and G.R. Tomlinson. Structure integrated sensing and related signal processing for condition-based maintenance. Symp. on Condition-Based Maintenance for Highly Engineered Systems, sep 2000.

[CCXW00] C.C. Chang, T.Y.P. Chang, Y.G. Xu, and M.L. Wang. Structural damage detection using an iterative neural network. of Intelligent Material Systems and Structures, 11(1):32-42, 2000.

[CG96] R. Carlin and E. Garcia. Parameter optimization of a genetic algorithm for structural damage detection. In Proceedings of the 14th International Modal Analysis Conference (IMAC), 2, pages 1292-1298, Dearborn, MI, feb 1996. Society for Experimental Mechanics, Inc, Bethel.

[CG01] J-H. Chou and J. Ghaboussi. Genetic algorithm in structural damage detection. Computers Es Structures, 79(14):1335-1353, jun 2001.

[Chu97] C.K. Chui. Wavelets: A Mathematical Tool for Signal Analysis. SIAM, Philadelphia, 1997.

[CI97] J. Cattariusa and D. J. Inmana. Time domain analysis for damage detection in smart structures. Mechanical Systems and Signal Processing, 11(3):409-423, may 1997.

[CS03a] C.C. Chang and Z. Sun. Locating and quantifying structure damage using spatial wavelet packet signature. In Shih-Chi Liu, editor, Smart Structures and Materials 2003: Smart Systems and Nondestructive Evaluation for Civil Infrastructures, volume 5057, pages 97105. SPIE, 2003.

[CS03b] P.T. Coverley and W.J. Staszewski. Impact damage location in composite structures using optimized sensor triangulation procedure. Smart Materials and Structures, 12:795-803, 2003.

[Cun98] P. Cunningham. CBR: Strengths and weaknesses. In J. Mira \& M. Ali A. P. del Pobil, editor, Lecture Notes in Artificial Intelligence 1416, number 2, pages 517-524, Benicàssim (Spain), 1998. 11 th International Conference on Industrial and Engineering Applications of Artificial Intelligence, Springer-Verlag. 
[DFP98] S.W. Doebling, C.R. Farrar, and M.B. Prime. A summary review of vibration-based damage identification methods. The Shock and Vibration Digest, 30(2):91-105, 1998.

[DH97] P. Demartines and J. Hérault. Curvilinear component analysis: a self-organizing neural network for nonlinear mapping of data sets. IEEE Transactions on Neural Networks, 8(1):148154., 1997.

[dMP97] R. Lopez de Mantaras and E. Plaza. Case-Based Reasoning: An overview. AI Communications, 10(1):21-29, 1997.

[EDH99] M. Ettouney, R. Daddazio, and A. Hapij. Optimal sensor locations for structures with multiple loading conditions. In Smart Structures and Materials 1999: Smart Systems for Bridges, Structures, and Highways, number 671, pages 78-89. Proceedings of SPIE, 1999.

[ELJ94] B. Edlund, P. Löfqvist, and P. Johansson. Case-Based Reasoning in bridge design. In 1st Workshop "Applications of Artificial Intelligence in Structural Engineering", pages 60-61, Lausanne, 1994. EG-SEA-AI.

[FB99] C.P. Fritzen and K. Bohle. Identification of damage in large scale structures by means of measured frfs-procedure and application to the i40-highway bridge,. In Damage Assessment of Structures, Proceedings of the International Conference on Damage Assessment of Structures (DAMAS'99), pages 310-319, Dublin, Ireland, 1999.

[FDDN99] C.R. Farrar, T.A. Duffey, S.W. Doebling, and D.A. Nix. A statistical pattern recognition paradigm for vibration based structural health monitoring. Structural Health Monitoring, pages $764-773,1999$.

[FDN01] C. R. Farrar, S. W. Doeblíng, and D. A. Nix. Vibration-based structural damage identification. Philosophical Transactions: Mathematical, Physical 6 Engineering Sciences, 359(1778):131-149, 2001.

[FI99] M.I. Friswell and D.J. Inman. Sensor validation for smart structures. Journal of Intelligent Material Systems and Structures, 10:973-982, 1999.

[FK04] C.P. Fritzen and K. Bohle K. Damage identification using a modal kinetic energy criterion and "output-only" modal data-application to the z24-brigde. In Proc. of the 2nd European Workshop on Structural Health Monitoring, pages 185-194, Munich, Germany, 2004.

[FM01] M.I. Friswell and J.E. Mottershead. Inverse methods in structural health monitoring,. In Damage Assessment of Structures, Proceedings of the International Conference on Damage Assessment of Structures (DAMAS'01), pages 201-210, Cardiff, UK,, 2001.

[FP97] L. Faravelli and A.A. Pisano. A neural network approach to structure damage assessment. Intelligent Information Systems, 1997. IIS '97. Proceedings, pages 585 - 588, 1997.

[FPG98] M.I. Friswell, J.E.T. Penny, and S.D. Garvey. A combined genetic and eigensensitivity algorithm for the location of damage in structures. Computers and Structures, 69(5):547556 , dec 1998.

[FSF01] M.L. Fugate, H. Sohn, and R.C. Farrar. Vibration-based damage detection using statistical process control. Mechanical Systems and Signal Processing, 15(4):707-723, jul 2001.

[GK86] P. Geladi and B. Kowalski. Partial least-squares regression: A tutorial. Analytica Chimica Acta, 185:1-17, 1986.

[GL01] S. Goutterbroze and J. Lardies. On using the wavelet transform in model analysis. Mech. Res. Commun, 28(5):561-569, 2001.

[HCSW05] J. Haywood, P.T. Coverley, W.J. Staszewski, and K. Worden. An automatic impact monitor for a composite panel employing smart sensor technology. Smart Materials and Strcutures, 14:265-271, 2005. 
[HF03] S. Han and B.F. Feeny. Application of proper orthogonal decomposition to structural vibration analysis. Mechanical Systems and Signal Processing, 17:989-1001, 2003.

[HH01] Z. Hou and A. Hera. A system identification technique using pseudo-wavelets. Journal of Intelligent Material Systems and Structures, 12(10):681-687, 2001.

[HNR00] Z. Huo, M. Noori, and R.S.Amand. Wavelet-based approach for structural damage detection. Journal of Engineering Mechanics, 126(7):677-683, jul 2000.

[Hos88] A. Hoskuldsson. PLS regresion methods. Journal of Chemometrics, 2(3):211-228, 1988.

[HS90] P. Hajela and F.J. Soeiro. Recent developments in damage detection based on system identification methods. Structural Optimization, 2:1-10, 1990.

[HSG95] J. Holnicki-Szulc and J.T. Gierlinski. Structural Analysis, Design and Control by the Virtual Distortion Method. J. Wiley \& Sons, Chichester, U.K, 1995.

[HSKN05] J. Holnicki-Szulc, P. Kolakowski, and N. Nasher. Leakage detection in water networks. Journal of Intelligent Material Systems and Structures, 16(3):207-219, 2005.

[HW03] M. Haase and J. Widjajakusuma. Damage identification based on ridges and maxima lines of wavelet transform. International journal of engineering science, 41(13-14):1423-1443, aug 2003.

[HX02] H. Hao and Y. Xia. Vibration-based damage detection of structures by genetic algorithm. Journal of computing in civil engineering, 16(3):222-229, 2002.

[JSFK95] R.T. Jones, J.S. Sirkis, E.J Friebele, and A.D. Kersey. Location and magnitude of impact detection in composite plates using neural networks. In William B. Spillman, editor, Proc. SPIE Vol. 2444, Smart Structures and Materials 1995: Smart Sensing, Processing, and Instrumentation, pages 469-480, apr 1995.

[JW88] R.A. Johnson and D.W. Wichern. Applied Multivariate Statistical Analysis. 0-130-41146-9. Prentice-Hall, Inc, Upper Saddle River, NJ, USA, third edition, 1988.

[KBGW05] G. Kerschen, P. De Boe, J.C. Golinval, and K. Worden. Sensor validation using principal component analysis. Smart Materials and Structures, 14:36-42, 2005.

[KF00] R. Kappagantu and B.F. Feeny. Dynamical characterization of a frictionally excited beam. Nonlinear Dynamics, 22:317-333, 2000.

[KK96] H.S. Kumar and C.S. Krishnamoorthy. Case-Based Reasoning in bridge design. In Advances in Computational Structures Technology, pages 197-205, Budapest (Hungary), 1996. Third International Conference in Computational Structures Technology, Civil-Comp Press.

[KMV05] P. Kolakowski, L.E. Mujica, and J. Vehí. Comparison of two software tools for damage identification: Gradient-based vs. Case-Based approach. Key Engineering Materials, 293:103-110, jul 2005.

[Koh90] T. Kohonen. The self-organizing map. Proceeding in IEEE, 78(9):1464-1480, 1990.

[Kol93] J. Kolodner. Case-Based Reasoning. Morgan Kaufmann Publishers, Inc., California, 1993.

[Kol04a] P. Kolakowski. Damage identification by the static virtual distortion method,. Engineering Transactions, 52(4):253-270, 2004.

[Kol04b] P. Kolakowski. Damage identification in beams by piezodiagnostics. In Proc. of the 2nd European Workshop on Structural Health Monitoring, pages 775-782, Munich, Germany, 2004.

[KZHS04] P. Kolakowski, T.G. Zielinski, and J. Holnicki-Szulc. Damage identification by the dynamic virtual distortion method. Journal of Intelligent Material Systems and Structures, 15(6):479493, 2004. 
[Lea96] D.B. Leake. Case-Based Reasoning: Experiences, Lessons, and Future Directions. AAAI Press, Menlo Park, CA, 1996.

[LHWW04] J. LeClerc, J. Haywood, W.Satszewski, and K. Worden. Impact detection in an aircraft composite panel - a neural approach. In C. Boller and W.J. Satszewski, editors, Proceeding of 2nd European Conference on Structural Health Monitoring, pages 407-414. University of Sheffield, DEStech Publications, Inc., 2004.

[LKG01] V. Lenaerts, G. Kerschen, and J.C. Golinval. Proper orthogonal decomposition for model updating of non-linear mechanical systems. Mechanical Systems and Signal Processing, 15:3143, 2001.

[LLV04] J.A. Lee, A. Lendasse, and M. Verleysen. Nonlinear projection with curvilinear distances: Isomap versus curvilinear distance analysis. Neurocomputing, 57:49-76, 2004.

[LM96] M.S. Lehane and C. J. Moore. Applying Case-Based Reasoning in bridge design. In B. Kumar, editor, Information Processing in Civil and Structural Engineering, pages 1-5. Inverleith Spottiswoode, 1996.

$\left[\mathrm{LPW}^{+} 01\right] \quad$ N. Liu, J.E.T. Penny, C.Y. Wei, P.E. Irving, N.D. Dykes, and Q.M. Zhu. Impact location on stiffened composite structures using neural networks. Key Engineering Materials, 204205:395-408, 2001.

[LR69] J.M. Lifshitz and A. Rotem. Determination of reinforcement unbonding of composites by a vibration technique. Journal of Composite Materials, 3:412-423, 1969.

[LZ93] C. Larson and D.C. Zimmerman. On the use of genetic algorithms in structural damage detection. In Proceedings of the 11th International Modal Analysis Conference, pages 10831094, Orlando, FL, feb 1993.

[LZ99] F.P. Lopez and D.C. Zimmerman. A pattern recognition approach for damage localization. Proceedings 17th International Modal Analysis Conference, pages 579-585, 1999.

[Mal99] S. Mallat. A Wavelet Tour of Signal Processing. Acedemic Press, 2nd edition, 1999.

[Mar01a] T. Marwalla. Probabilistic fault identification using a committee of neural networks and vibration data. American Institute of Aeronautics and Astronautics, Journal of Aircraft, 38(1):138-146, feb 2001.

[Mar01b] T. Marwalla. Probabilistic fault identification using vibration data and neural networks. Mechanical Systems and Signal Processing, 15(6):1109-1128, 2001.

[MC03] J. Melendez and J. Colomer. Inteligencia artificial para la detección y el diagnóstico de fallos. Automática e Instrumentación, 340:2-7, mai 2003.

[MDS00] J. Main, T.S. Dillon, and S.C.K. Shiu. A tutorial on Case Based Reasoning. In S.K. Pal, T.S. Dillon, and D.S. Yeung, editors, Soft Computing in Case Based Reasoning, pages 1-28, London, UK, 2000. Springer.

[MFL00] E. Monaco, F. Franco, and L. Lecce. Experimental and numerical activities on damage detection using magnetostrictive actuators and statistical analysis. Journal of Intelligent Material Systems and Structures, 11(7):567-578, 2000.

[MLSS04] L. Mallet, B.C. Lee, W.J. Staszewski, and F. Scarpa. Structural health monitoring using scanning laser vibrometry: Ii. lamb waves for damage detection. Smart Materials and Structures, 13(2):261-269, 2004.

[MML92] E. Martin, J. Morris, and S. Lane. Monitoring process manufacturing performance. IEEE Control Systems Magazine, 22(5):26-39, oct 1992.

[MN02] K. Moslem and R. Nafaspour. Structural damage detection by genetic algorithms. AIAA, 40(7):1395-1401, jul 2002. 
[MR99] J. Maeck and G. De Roeck. Dynamic bending and torsion stiffness derivation from modal curvatures and torsion rates. Journal of Sound and Vibration, 255(1):153-170, 1999.

[MR03] J. Maeck and G. De Roeck. Damage assessment using vibration analysis on the z24 bridge. Mechanical Systems and Signal Processing, 71(1):133-142, 2003.

[MS96] C. Mares and C. Surace. An application of genetic algorithms to identify damage in elastic structures. Journal of Sound and Vibration, 195(2):195-215, aug 1996.

[Mur00] G. Muravin. Inspection, diagnostics and monitoring of construction materials by the acoustic emission methods. Minerva Press, London, 2000.

$\left[\mathrm{MVR}^{+} 04\right]$ L.E. Mujica, J. Vehí, J. Rodellar, O. Garcia, and P. Kolakowski. A hybrid knowledge based reasoning approach for structural assessment. In C. Boller and W.J. Satszewski, editors, Proceeding of 2nd European Conference on Structural Health Monitoring, pages 591-598. University of Sheffield, DEStech Publications, Inc., 2004.

[MVRK05] L.E. Mujica, J. Vehí, J. Rodellar, and P. Kolakowski. A hybrid approach of knowledgebased reasoning for structural assessment. Smart Materials and Structures, 14:1554-1562, nov 2005.

[MVSW06] L.E. Mujica, J. Vehí, W. Staszewski, and K. Worden. Impact damage detection in aircraft composites using knowledge-based reasoning. submitted to Structural Health Monitoring, an International Journal, 2006.

[NM94] P. Nomikos and J.F. MacGregor. Monitoring batch processes using multiway principal component analysis. AIChE Journal, 40(8):1361-1375, aug 1994.

[NM95] P. Nomikos and J.F. MacGregor. Multi-way partial least squares in monitoring batch processes. Chemometrics and Intelligent Laboratory Systems, 30:97-198, mai 1995.

[NY93] H.G. Natke and J.T.P. Yao. Detection and location of damage causing non-linear system behaviour. In H.G. Natke, G.R. Tomlinson, and J.T.P. Yao, editors, Proc. of the Internat. Workshop on "Safety Evaluation Based on Identification Approaches Related to Time Variant and Nonlinear Structures", Lambrecht, 1993. Vieweg, Braunschweig.

[PFMR00] B.A.D Piombo, A. Fasana, S. Marchesiello, and M. Ruzzene. Modelling and identification of dynamic response of a supported bridge. Mechanical System and Signal Processing, 14(1):7589 , jan 2000.

[PK99] S. Pittner and S.V. Kamarthi. Feature extraction from wavelet coefficients for pattern recognition tasks. Pattern Analysis and Machine Intelligence, IEEE Transactions on, 21(1):83-88, jan 1999 .

[RCB00] E.L. Russell, L.H. Chiang, and R.D. Braatz. Data-Driven Methods for Fault Detection and Diagnosis in Chemical Processes (Advances in Industrial Control). 1-85233-258-1. Springer, London, 2000.

[RL95] J. Rhim and S.W. Lee. A neural network approach for damage detection and identification of structures. Computational mechanics, 16(6):437-443, nov 1995.

[RL03] A. Raich and T. Liszkai. Benefits of implicit redundant genetic algorithms for structural damage detection in noisy environments. In Cantú-Paz, Foster, Deb, Davis, Roy, O'Reilly, Beyer, Standish, and Kendall, editors, Genetic and Evolutionary Computation - GECCO2003, number 2724 in LNCS, pages 2418-2419, ChicagO, sep 2003. Springer-Verlag.

[RNRS02a] Y. Robert-Nicoud, B. Raphael, and I. Smith. Decision support for system identification. In M. Schnelleenbach-Held and H. Denk, editors, Advances in Intelligent Computing in Engineering, volume 4 of 4, pages 92-101, Fortschritt-Berichte, 2002. 9th International Workshop of the European Group of Intelligent Computing in Engineering (EG-ICE), VDI Verlag Düsseldorf. 
[RNRS02b] Y. Robert-Nicoud, B. Raphael, and I. Smith. A methodology for model selection using measurements. 3rd International conference on Decision Making in Civil and Urban Engineering (DMinUCE), CD-ROM, 2002.

[Ros99] J.L. Rose. Ultrasonic waves in solid media. Cambridge University Press, Cambridge, 1999.

[RS97] R. Ruotolo and C. Surace. Damage assessment of multiple cracked beams: Numerical results and experimental validation. Journal of Sound and Vibration, 206(4):567-588, oct 1997.

[RS98] B. Raphael and I. Smith. Finding the right model for bridge diagnosis. In Ian Smith, editor, AI in Structural Engineering, number 1454 in Lecture Notes in Computer Science, pages 308-319. Springer, 1998.

[RVS ${ }^{+}$06] M. Ruiz, M. Villez, G. Sin, J. Colomer, and P. Vanrrolleghem. Different PCA aproaches for monitoring nutrient removing batch process: Pros and cons. Submitted to American Institute of Chemical Engineers Journal (AIChE), 2006.

[Ryt93] A. Rytter. Vibration Based Inspection of Civil Engineering Structures. PhD thesis, Department of Building Technology and Structural Engineering. Aalborg University, Denmark, 1993.

[Sam69] J.W. Sammon. A nonlinear mapping algorithm for data structure analysis. IEEE, Transactions on Computers, C-18:401-409, 1969.

[SBT04] W.J. Staszewski, C. Boller, and G.R. Tomlinson. Health Monitoring of Aerospace Structures: Smart Sensor Technologies and Signal Processing. John Wiley \& Sons, Ltd, Chichester, 2004.

[SCF00] H. Sohn, J.A. Czarnecki., and C.F. Farrar. Structural health monitoring using statistical process control. Journal of Structural Engineering, 126(1):1356-1363, 2000.

[SG96] N. Stubbs and N. Garcia. Application of pattern recognition to damage localization. Journal of Computer-Aided Civil and Infrastructure Engineering, 11(6):395-409, dec 1996.

[She62a] R.N. Shepard. The analysis of proximities: Multidimensional scaling with unknown distance functions, part i. Psychometrika, 27:125-140, 1962.

[She62b] R.N. Shepard. The analysis of proximities: Multidimensional scaling with unknown distance functions, part ii. Psychometrika, 27:219-246, 1962.

[SK03] Q. Shan and G. King. Fuzzy techniques for impact locating and magnitude estimating. Insight - Non-Destructive Testing and Condition Monitoring, 45(3):190-195, mar 2003.

[Smi02] L. Smith. A tutorial on principal components analysis. Technical report, University of Otago (New Zeland), feb 2002.

[Sta97a] W.J. Staszewski. Identification of damping in mdof systems using time-scale decomposition. Journal of Sound and Vibration, 203(2):283-305, jul 1997.

[Sta97b] W.J. Staszewski. Vibration data compression with optimal wavelet coefficients. In IEEE, editor, Genetic Algorithms In Engineering Systems:Innovations and Applications, 1997. GALESIA 97. Second International Conference, number 446, pages 186-190, Glasgow, UK, sep 1997.

[Sta98a] W..J. Staszewski. Identification of non-linear system using multi-scale ridges and skeletons of the wavelet transform. Journal of Sound and Vibration, 214(4):639-658, 1998.

[Sta98b] W.J. Staszewski. Wavelet based compression and feature selection for vibration. Journal of Sound and Vibration, 211(5):735-760, apr 1998.

[Sta01] W.J. Staszewski. Monitoring on-line integrated technologies for operational reliability monitor. Air \& Space Europe, 2(4):67-72, jul 2001. 
[Sta02] W.J. Staszewski. Intelligent signal processing for damage detection in composite. Composites Science and Technology, 62(7-8):941-950, jun 2002.

[Sta03] W.J. Staszewski. Structural health monitoring using guided ultrasonic wave. In C. A. Mota Soares J. Holnicki-Szulc, editor, Advances in Smart Technologies in Structural Engineering, pages 117-162. Springer, 2003.

[SWF02] H. Sohn, K. Worden, and C.R. Farrar. Statistical damage classification under changing environmental and operational conditions. Journal of Intelligent Material Systems and Structures, 13(9):561-574, 2002.

[SWWT00] W.J. Staszewski, K. Worden, R. Wardle, and G.R. Tomlinson. Fail-safe sensor distributions for impact detection in composite materials. Samrt Materials and Structures, 9:298-303, 2000.

[TC98a] M. Tracy and F.K. Chang. Identifying impacts in composite plates with piezoelectric strain sensors, part 1: Theory. Journal of Intelligent Material Systems and Structures, 9(11):920928 , nov 1998.

[TC98b] M. Tracy and F.K. Chang. Identifying impacts in composite plates with piezoelectric strain sensors, part 2: Experiment. Journal of Intelligent Material Systems and Structures, 9(11):929-937, nov 1998.

[TH03] I. Trendafilova and W. Heylen. Categorisation and pattern recognition methods for damage localisation from vibration measurements. Mechanical system and signal processing, $17(4): 825-836$, jul 2003.

[TR04] A. Teughels and G. De Roeck. Structural damage identification of the highway bridge z24 by fe model updating,. Journal of Sound and Vibration, 278(3):589-610, 2004.

[Ver01] M. Verleysen. Machine learning of high-dimensional data: local artificial neural networks and the curse of dimensionality. Agregation in higher education thesis, Université Catholique de Louvain, Louvain-la-Neuve, feb 2001.

[Ver03] M. Verleysen. Limitations and future trends in neural computation, volume 186, chapter Learning high-dimensional data, pages 141-162. IOS Press, Amsterdam (The Netherlands), 2003.

[WA99] E.J. Williams and Messina A. Applications of the multiple damage location assurance criterion. In Damage Assessment of Structures, Proceedings of the International Conference on Damage Assessment of Structures (DAMAS'99, pages 256-264, Dublin, Ireland, 1999.

[Wat97] I. Watson. Applying Case-Based Reasoning: Techniques for Enterprise Systems. Morgan Kaufman Publishers, jul 1997.

[Wat98] I. Watson. CBR is a methodology not a technology. In R. Miles, M. Moulton, and M. Bramer, editors, Research $\&$ Development in Expert Systems XV, pages 213-223, London, 1998. Springer.

[WB01] K. Worden and A.P. Burrows. Optimal sensor placement for fault detection. Engineering Structures, 23:885-901, 2001.

[WGEh87] S. Wold, P. Geladi, K. Esbensen, and J. Öhman. Multiway pincipal component and PLS analysis. Journal of Chemometrics, 1:41-56, 1987.

$\left[\mathrm{WGW}^{+} 99\right]$ B.M. Wise, N.B. Gallagher, S. Watts, D.D. White, and G.G. Barna. A comparison of PCA, Multiway PCA, trilinear decomposition and parallel factor analysis for fault detection in a semiconductor etch process. Journal of Chemometrics, 13:379-396, 1999.

[WKM99] J. Westerhuis, T. Kourti, and J. MacGregor. Comparing alternative approaches for multivariate statistical analysis of batch process data. Journal of Chemometrics, 13:397-413, 1999. 
[WM99] K. Worden and G. Manson. Visualization and dimension reduction of high-dimensional data for damage detection. imac 17. In S. Ganeriwalaand S. Patel and H. Hartung, editors, Proceedings of the 17th International Modal Analysis Conference, pages 1576-1585, 1999.

[WM00] K. Worden and G. Manson. Damage identification using multivariate statistics: kernel discriminant analysis. Inverse Problems in Engineering, 8:25-46, 2000.

[WMA01] K. Worden, G. Manson, and D. Allman. An experimental appraisal of the strain energy damage location method. In Damage Assessment of Structures, Proceedings of the International Conference on Damage Assessment of Structures (DAMAS'01), pages 35-46, Cardiff, $\mathrm{UK}, 2001$.

[WMF00] K. Worden, G. Manson, and N.R.J. Fieller. Damage detection using outlier analysis. Journal of Sound and Vibration, 229(3):647-667, jan 2000.

[Wor97] K. Worden. Structural fault detection using a novelty measure. Journal of Sound and Vibration, 201(1):85-101, mar 1997.

[WS00] K. Worden and W.J. Staszewski. Impact location and quantification on a composite panel using neural networks and a genetic algorithm. Strain, (36):61-70, 2000.

[WXL00] M.L. Wang, F.L. Xu, and G.M. Lloyd. A systematic numerical analysis of the damage index method used for bridge diagnostics. In Smart Structures and Materials 2000: Smart Systems for Bridges, Structures, and Highways, number 988, pages 154-164, Newport Beach, California,, WXL00. Proceedings of SPIE.

[YE99] Ho Y.K and D.J. Ewins. Numerical evaluation of the damage index,. In Structural Health Monitoring 2000, pages 995-1011, Palo Alto, California, 1999. Stanford University,.

[YL99] S.M. Yang and G.S. Lee. Effects of modeling error on structure damage diagnosis by twostage optimization. In F.K. Chang, editor, Structural Health Monitoring, pages 871-880, Palo Alto, California, 1999. Stanford University.

[YYJ03] L.H. Yam, Y.J. Yana, and J.S. Jiang. Vibration-based damage detection for composite structures using wavelet transform and neural network. Composite Structures, 60(4):403412 , jun 2003.

[YZ98] K.C. Yap and D.C. Zimmerman. The effect of coding on genetic algorithm based structural damage detection. In Proceedings of the 16th International Modal Analysis Conference, number 1, pages 165-171, Santa Barbara, CA, feb 1998. Society for Experimental Mechanics, Inc, Bethel.

[ZB93] G.L. Zheng and S.A. Billings. Fault diagnosis using radial basis function neural networks. Technical report, Department of Automatic Control and Systems Engineering, University of Sheffield, 1993.

[ZI01] C. Zang and M. Imregun. Structural damage detection using artificial neural networks and measured frf data reduced via principal component projection. Journal of Sound and Vibration, 242(5):813-827, 2001.

[ZQL99] L. Zhang, W. Quiong, and M. Link. A structural damage identification approach based on element modal strain energy. In Proceedings of ISMA23, Noise and Vibration Engineering,, Leuven, Belgium, 1999. 